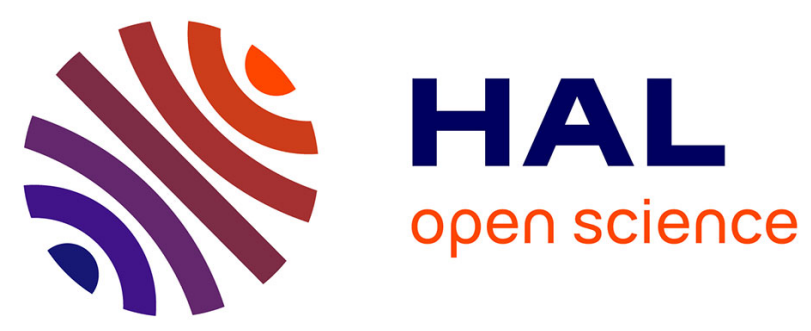

\title{
Controlled bi-functionalization of silica microbeads through grafting of amidoxime/methacrylic acid for $\mathrm{Sr}(\mathrm{II})$ enhanced sorption
}

Yuezhou Wei, Makpal Rakhatkyzy, Khalid A.M. Salih, Kaituo Wang, Mohammed Hamza, Eric Guibal

\section{To cite this version:}

Yuezhou Wei, Makpal Rakhatkyzy, Khalid A.M. Salih, Kaituo Wang, Mohammed Hamza, et al.. Controlled bi-functionalization of silica microbeads through grafting of amidoxime/methacrylic acid for $\mathrm{Sr}(\mathrm{II})$ enhanced sorption. Chemical Engineering Journal, 2020, 402, pp.125220. 10.1016/j.cej.2020.125220 . hal-02905275

\section{HAL Id: hal-02905275 \\ https://hal.mines-ales.fr/hal-02905275}

Submitted on 14 Jun 2021

HAL is a multi-disciplinary open access archive for the deposit and dissemination of scientific research documents, whether they are published or not. The documents may come from teaching and research institutions in France or abroad, or from public or private research centers.
L'archive ouverte pluridisciplinaire HAL, est destinée au dépôt et à la diffusion de documents scientifiques de niveau recherche, publiés ou non, émanant des établissements d'enseignement et de recherche français ou étrangers, des laboratoires publics ou privés. 


\title{
Controlled bi-functionalization of silica microbeads through grafting of amidoxime/methacrylic acid for Sr(II) enhanced sorption
}

\author{
Yuezhou Wei $^{\mathrm{a}, \mathrm{b}, 1}$, Makpal Rakhatkyzy ${ }^{\mathrm{a}, 2}$, Khalid A.M. Salih ${ }^{\mathrm{a}, 3}$, Kaituo Wang ${ }^{\mathrm{a}, 5}$, \\ Mohammed F. Hamza ${ }^{\mathrm{a}, \mathrm{c}, *, 4}$, Eric Guibal ${ }^{\mathrm{d}, *, 6}$ \\ ${ }^{a}$ Guangxi Key Laboratory of Processing for Non-ferrous Metals and Featured Materials, School of Resources, Environment and Materials, Guangxi University, Nanning 530004, PR China \\ ${ }^{\mathrm{b}}$ Shanghai Jiao Tong University, Shanghai, PR China \\ ${ }^{\mathrm{c}}$ Nuclear Materials Authority, POB 530, El-Maadi, Cairo, Egypt \\ ${ }^{\mathrm{d}}$ Polymers Composites and Hybrids (PCH), IMT Mines Ales, Alès, France
}

H I G H L I G H T S

- Bi-functionalization of silica particles increases $\mathrm{Sr}$ (II) sorption properties.

- Methacrylic (80\%)/amidoxime (20\%) substitution ratio is optimum.

- Maximum sorption capacity reaches $1.57 \mathrm{mmol} \mathrm{Sr} \mathrm{g}^{-1}$ at $\mathrm{pH} 8$.

- Total Sr(II) desorption and weak loss in sorption properties at the fifth recycling.

- The sorbent is remarkably selective to Sr(II) in seawater.
G R A P H I C A L A B S T R A C T

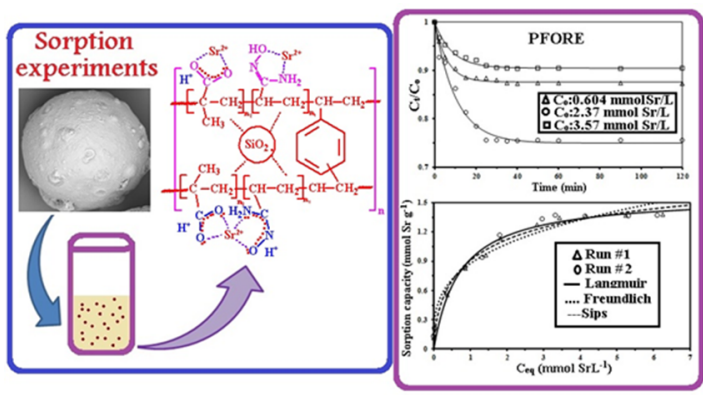

\begin{abstract}
A B S T R A C T
Silica microspheres are functionalized through the grafting of either polymethacrylic acid or amidoxime groups (mono-functional composite, $\mathrm{PMAA} / \mathrm{SiO}_{2}$ and $\mathrm{PAO} / \mathrm{SiO}_{2}$, respectively) or in combination (bi-functional composite, $\mathrm{PAO}_{\mathrm{x}} \mathrm{MAA}_{100-\mathrm{x}} / \mathrm{SiO}_{2}$ ). The materials are characterized by textural analysis, TGA, SEM-EDX, elemental analysis, FTIR, XPS, $\mathrm{pH}_{\mathrm{PZC}}$ in order to confirm the synthesis route, identify the reactive groups and support the interpretation of sorption mechanisms toward $\mathrm{Sr}(\mathrm{II})$. The sorption of $\mathrm{Sr}(\mathrm{II})$, at optimum $\mathrm{pH}$, involves amine groups and hydroxyl/carboxyl groups in the bi-functional composite sorbent. The comparison of sorption properties shows that maximum sorption requires a majority of carboxylic groups from polyacrylic compared with amidoxime functions; optimum formulation: $\mathrm{PAO}_{20} \mathrm{MAA}_{80} / \mathrm{SiO}_{2}$ sorbent. Sorption isotherms are efficiently

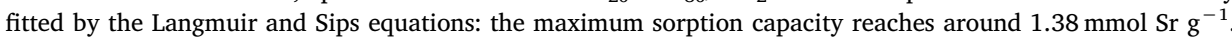
Kinetic profiles for sorption are modeled using the pseudo-first order rate equation; equilibrium is achieved within 40-60 min. Complete desorption of Sr(II) using $1 \mathrm{M} \mathrm{HCl}$ solutions is even faster; equilibrium time being
\end{abstract}

\footnotetext{
* Corresponding authors.

E-mail addresses: yzwei@gxu.edu.cn (Y.Wei), mak_rakh@mail.ru (M. Rakhatkyzy), Immortaltiger7@gmail.com (K.A.M. Salih),

wangkaituo@gxu.edu.cn (K. Wang), m_fouda21@hotmail.com (M.F. Hamza), eric.guibal@mines-ales.fr (E. Guibal).

${ }^{1}$ ORCID: 0000-0003-3821-9078.

${ }^{2}$ ORCID: 0000-0001-6365-8916.

${ }^{3}$ ORCID: 0000-0001-6117-6753.

${ }^{4}$ ORCID: 0000-0002-8935-6884.

${ }^{5}$ ORCID: 0000-0002-6756-8413.

${ }^{6}$ ORCID: 0000-0002-2767-6305.
} 
15-20 min. The sorbent can be recycled for 5 cycles with a limited decrease in the sorption performance, and full desorption. In fixed-bed column, the breakthrough curves are fitted by the Thomas equation. In multi-component solutions, the sorbent shows a preferred selectivity according the sequence: $\mathrm{K}$ (I) $>\mathrm{Ba}$ (II) $>\mathrm{Na}$ (I) $>\mathrm{Ca}$ (II). Tested on seawater, the sorbent shows high distribution ratio for $\mathrm{Sr}(\mathrm{II}), \mathrm{B}(\mathrm{III})$ and $\mathrm{Mo}(\mathrm{VI})$

\section{Introduction}

The removal of strontium from water bodies has recently retained increasing attention from scientific community due to Fukushima Daiichi NPP accident $[1,2]$. The dissemination of radioactive strontium may cause serious health and life hazards due to accumulation in soils [3] and bioaccumulation in the food chain [4]. Apart this accidental dispersion of hazardous ${ }^{90} \mathrm{Sr}$, the metal is used in fireworks, optical materials including TV tube monitor, ferrite magnets, ceramics and the manufacturing of some toothpastes [5]. Majors threats for human health concern direct radiotoxicity (after nuclear accident), bones diseases (associated with Ca replacement with $\mathrm{Sr}$ ) causing different types of cancer, anemia, and leukemia [5].

Precipitation coupled with microfiltration has been investigated for the recovery of $\operatorname{Sr}(\mathrm{II})[6,7]$. Solvent extraction was also used $[8,9]$. However, sorption processes have retained much more attention, playing with a wide diversity of supports. Carbon-based sorbents have been investigated for Sr(II) uptake from surface waters [10-13]. Biosorbents and biopolymers showed also promising properties for strontium uptake. [14-18]. Zeolite, silica and clays have been used under their raw form [19-22], after chemical modification [23-27], magnetite incorporation [5,28], or extractant impregnation [29]. Sorbents impregnated with Prussian Blue and analogues have also been successfully tested for Sr(II) removal $[30,31]$. Metal and bi-metallic nanoparticles have been applied to the recovery of cesium and strontium from simulated effluents contaminated with radioelements [32,33]. Functionalized polymer resins were widely investigated for $\mathrm{Sr}$ (II) recovery [3436].

Composite organic/inorganic resins have shown promising perspectives combining the mechanical stability of silica core (for example) and highly reactive and selective functionalities of the polymer layer (which can be tailored for specific metal target) [27]. In the case of Sr(II) sorption, the coating of silica core may be based on the grafting of polymers bearing carboxylic-acid moieties [27] (maximum sorption capacity, $\mathrm{q}_{\mathrm{m}}$ : increased with temperature up to $92 \mathrm{mg} \mathrm{Sr}^{-1}$ ). Indeed, carboxylic acid groups proved being efficient in enhancing the sorption properties of different supports [37] $\left(\mathrm{q}_{\mathrm{m}}: 58.5 \mathrm{mg} \mathrm{Sr}^{-1}\right)$, including directly on carboxylate groups of alginate beads [38] ( $\mathrm{q}_{\mathrm{m}}: 110 \mathrm{mg} \mathrm{Sr}$ $\mathrm{g}^{-1}$ ). Amidoxime reactive groups have also shown high affinity for $\mathrm{Sr}$ (II) on synthetic polymers [39], on chitosan-based supports $\left(\mathrm{q}_{\mathrm{m}}: 153 \mathrm{mg}\right.$ Sr $\left.\mathrm{g}^{-1},[40]\right)$ or composite algal/PEI beads $\left(\mathrm{q}_{\mathrm{m}}: 189 \mathrm{mg} \mathrm{Sr} \mathrm{g}^{-1},[41]\right)$. Several studies over the last decades have demonstrated the benefits of bi-functionality on metal sorption properties [42-51]. In the case of sulfonic/carboxylic resin, Younis et al. [43] reported sorption capacities as high as $175 \mathrm{mg} \mathrm{Sr} \mathrm{g}^{-1}$. This work contributes to the development of bi-functional sorbents for the sorption of $\mathrm{Sr}(\mathrm{II})$. Silica particles are coated with polymethacrylic acid (PMAA/ $\mathrm{SiO}_{2}$ ), polyacrylonitrile $\left(\mathrm{PAN} / \mathrm{SiO}_{2}\right)$, or amidoximated polyacrylonitrile $\left(\mathrm{PAO} / \mathrm{SiO}_{2}\right)$ (monofunctionalized silica); the sorption properties are compared with a series of bi-functionalized silica composite (with different fractions of methacrylic acid and amidoxime moieties, $\mathrm{PAO}_{\mathrm{x}} \mathrm{MAA}_{100-\mathrm{x}} / \mathrm{SiO}_{2}$ ).

The major outcomes of this work consist of the synthesis of mechanically stable sorbents (based on silica core), with enhanced reactivity (due to the combined effects of methacrylic acid and amidoxime bifunctionality). The optimization of the ratio of reactive moieties brings new insights in the promising perspectives opened by bi-functionality.

In the first part of the work, the materials are characterized using BET and TGA analysis, elemental analysis, FTIR and XPS spectroscopies, and titration (for the determination of $\mathrm{pH}_{\mathrm{PZC}}$ ). In the second part of the work, the sorption of $\operatorname{Sr}(\mathrm{II})$ is investigated through the study of $\mathrm{pH}$ effect, uptake kinetics, sorption isotherms, metal desorption and sorbent recycling, and sorption in multi-component solutions (sorption selectivity) in batch reactors. The effect of flow rate on Sr(II) sorption in dynamic system (fixed-bed columns) is also investigated. Finally, $\mathrm{PAO}_{20} \mathrm{MAA}_{80} / \mathrm{SiO}_{2}$ composite sorbent is tested for the removal of Sr(II) from seawater; in an attempt to simulate the recovery of ${ }^{90} \mathrm{Sr}$ (II) from radioactive contaminated effluent.

\section{Materials and methods}

\subsection{Materials}

Strontium nitrate, potassium peroxydisulfate, sodium pyrosulfite, ethanol (absolute), sodium carbonate anhydrous, and salts of barium chloride dihydrate $\left(\mathrm{BaCl}_{2} \cdot 2 \mathrm{H}_{2} \mathrm{O}\right)$, potassium chloride $(\mathrm{KCl})$, sodium chloride $(\mathrm{NaCl})$ and anhydrous calcium chloride $\left(\mathrm{CaCl}_{2}\right)$, used for preparing multi-component solutions, were supplied by Guangdong Guanghua Sci-Tech Co., Ltd., Shantou, Guangdong, China. Stock solutions were prepared at the concentration of $1 \mathrm{~g} \mathrm{~L}^{-1}$ using ultrapure water (UPW). Working solutions were diluted to the assigned concentration using UPW just before use. Hydroxylammonium chloride, methyl cellulose (MC) and polyvinyl alcohol (PVA) were purchased from Shanghai Test Sihewei Chemical Co., Ltd. (Shanghai, China). Silica micro-beads were supplied by Asahi Chemicals, Co Ltd. (Osaka, Japan). Acrylonitrile (AN), divinylbenzene (DVB), nitric acid and hydrochloric acid were purchased from Sinopharm Chemical Reagent Co., Ltd (Shanghai, China).

Seawater for testing Sr(II) removal from complex solutions was collected from Fangchenggang, a prefecture-level city in the south of Guangxi Zhuang Autonomous Region, People's Republic of China, is located at the following coordinates: $21^{\circ} 36{ }^{\prime} \mathrm{N} 108^{\circ} 18^{\prime} \mathrm{E}$ (see MAP AM1, in Additional Material Section).

\subsection{Synthesis of sorbents}

\subsubsection{Mono-functionalized $/ \mathrm{SiO}_{2}$ sorbent}

2.2.1.1. Synthesis of polyacryl-amidoxime $/ \mathrm{SiO}_{2}$ sorbent. A three-necked round bottom flask, heated using a silicone oil bath, was equipped with a condenser and a mechanical stirrer, while the third necked was connected to a dropping funnel. For reducing synthesis costs, experimental conditions were adapted: water was used as the solvent in the polymerization reaction, while $\mathrm{K}_{2} \mathrm{~S}_{2} \mathrm{O}_{8}$ and $\mathrm{Na}_{2} \mathrm{~S}_{2} \mathrm{O}_{5}$ were selected as redox initiator.

2.2.1.1.1. Synthesis of polyacrylonitrile $/ \mathrm{SiO}_{2}$ sorbent - $\mathrm{PAN} / \mathrm{SiO}_{2}$ (Scheme 1a). The initiator solution was prepared by dissolving $0.5 \mathrm{~g}$ $\mathrm{K}_{2} \mathrm{~S}_{2} \mathrm{O}_{8}$ and $0.2 \mathrm{~g} \mathrm{Na}_{2} \mathrm{~S}_{2} \mathrm{O}_{5}$ in $10 \mathrm{~mL} \mathrm{UPW}$, under strong stirring, for $20 \mathrm{~min}$ at $22 \pm 2{ }^{\circ} \mathrm{C}$. Ten grams of porous silica particles were immersed in the mixture of $50 \mathrm{~mL}$ PVA solution $(1 \% \mathrm{w} / \mathrm{w})$ and $6 \mathrm{~mL} \mathrm{MC} \mathrm{solution}$ $(0.5 \% \mathrm{w} / \mathrm{w})$, under strong stirring $(250 \pm 5 \mathrm{rpm})$. In a second step, the suspension was drop wisely added to the solution containing both the crosslinker and the mixture of monomers (i.e., $1.4 \mathrm{~g} \mathrm{AN}+0.23 \mathrm{~g}$ of DVB). The reaction was maintained for $20 \mathrm{~min}$ at $40^{\circ} \mathrm{C}$, before increasing the temperature to $70^{\circ} \mathrm{C}$ for $2 \mathrm{~h}$; the final step took place at $90{ }^{\circ} \mathrm{C}$ for $7 \mathrm{~h}$. The final product, polyacrylonitrile/ $\mathrm{SiO}_{2}\left(\mathrm{PAN} / \mathrm{SiO}_{2}\right)$, was obtained after washing with hot water, acetone, and dried at $50{ }^{\circ} \mathrm{C}$ under vacuum for $12 \mathrm{~h}$.

2.2.1.1.2. Synthesis of polyacryl-amidoxime $/ \mathrm{SiO}_{2}$ sorbent - $\mathrm{PAO} / \mathrm{SiO}_{2}$ 


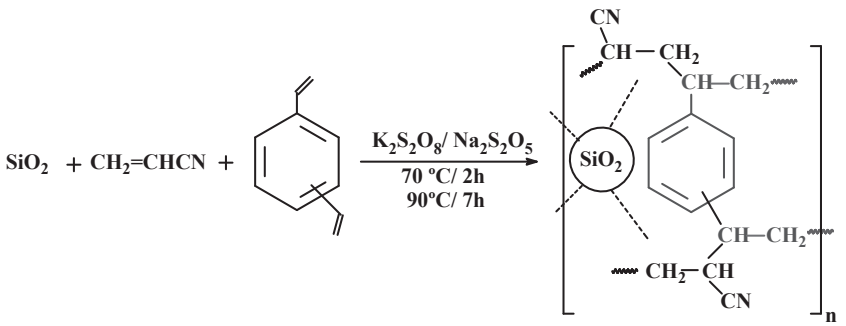

Scheme 1a. Synthesis route for the preparation of $\mathrm{PAN} / \mathrm{SiO}_{2}$.

(Scheme 1b). Four grams of $\mathrm{PAN} / \mathrm{SiO}_{2}$ were dispersed into $40 \mathrm{~mL}$ of water/ethanol mixture $(1: 1, \mathrm{v} / \mathrm{v})$. Fifteen $\mathrm{g}$ of hydroxylammonium chloride were dissolved in $100 \mathrm{~mL}$ of water/ethanol solution $(5: 1, \mathrm{v} / \mathrm{v})$ containing $7 \mathrm{~g}$ of $\mathrm{Na}_{2} \mathrm{CO}_{3}$. This solution was mixed with $\mathrm{PAN} / \mathrm{SiO}_{2}$ suspension for $20 \mathrm{~min}$ at $40^{\circ} \mathrm{C}$, before heating under reflux at $70{ }^{\circ} \mathrm{C}$ for $5 \mathrm{~h}$. The final product $\left(\mathrm{PAO} / \mathrm{SiO}_{2}\right)$ was dried under vacuum for $12 \mathrm{~h}$.

2.2.1.1.3. Synthesis of polymethacrylic acid/SiO $\mathrm{S}_{2}$ sorbent - PMAA/ $\mathrm{SiO}_{2}$ (Scheme 2). The synthesis followed exactly the same procedure as described above substituting acrylonitrile with methacrylic acid. The same ratios of monomers to additives were respected. Scheme 2 reports the synthesis route (for polymethacrylic acid (PMAA) functionalization).

\subsubsection{Bi-functionalized $/ \mathrm{SiO}_{2}$ sorbent}

2.2.2.0.1. Synthesis of polyacrylonitrile/methacrylic acid sorbent with different ratios (Scheme 3). The bi-functionalization of $\mathrm{SiO}_{2}$ was processed first by simultaneously grafting PAN and PMAA moieties. Ten $g$ of silica micro-beads were mixed with $50 \mathrm{~mL}$ of PVA solution $(1 \%, \mathrm{w} / \mathrm{w})$ completed with MC solution ( $6 \mathrm{~mL}, 0.5 \% \mathrm{w} / \mathrm{w})$, followed by dropwise addition of $0.5 \mathrm{~g} \mathrm{~K}_{2} \mathrm{~S}_{2} \mathrm{O}_{8}$ and $0.2 \mathrm{~g} \mathrm{Na} \mathrm{S}_{2} \mathrm{O}_{5}$ (previously dissolved in $10 \mathrm{~mL}$ of water). The mixture was stirred $(250 \pm 5 \mathrm{rpm})$ at room temperature (i.e., $22 \pm 2{ }^{\circ} \mathrm{C}$ ) for $20 \mathrm{~min}$. The grafting of additional reactive groups was performed by dropwise addition of variable amounts of AN (i.e., $0.3 \mathrm{~g}, 0.7 \mathrm{~g}$ and $1.2 \mathrm{~g}$ ) and MAA (i.e., $1.2 \mathrm{~g}$, $0.7 \mathrm{~g}$ and $0.3 \mathrm{~g}$ ) in the presence of $0.25 \mathrm{~g}$ of DVB. The reaction was thermally processed in three steps: at $40^{\circ} \mathrm{C}$ for $20 \mathrm{~min}$, followed by $2 \mathrm{~h}$ at $70^{\circ} \mathrm{C}$ and finished at $90^{\circ} \mathrm{C}$ for $7 \mathrm{~h}$. The copolymer ratios varied to produce: $\mathrm{PAN}_{20} / \mathrm{MAA}_{80}, \mathrm{PAN}_{50} / \mathrm{MAA}_{50}$, and $\mathrm{AN}_{80} / \mathrm{MAA}_{20}$ respectively. The products $\left(\mathrm{PAN}_{\mathrm{x}} \mathrm{MAA}_{100-\mathrm{x}} / \mathrm{SiO}_{2}\right)$ were washed with hot water, acetone, before being dried at $50{ }^{\circ} \mathrm{C}$ under vacuum for $12 \mathrm{~h}$.

2.2.2.1. Synthesis of polyacryl-amidoxime/methacrylic acid sorbent with different ratios. The three samples of $\mathrm{PAN}_{\mathrm{x}} \mathrm{MAA}_{100-\mathrm{x}} / \mathrm{SiO}_{2}$ were amidoximated by reaction with hydroxyl ammonium hydrochloride at $70{ }^{\circ} \mathrm{C}$ for $5 \mathrm{~h}$, in the presence of sodium carbonate. Four $\mathrm{g}$ of polymer/ $\mathrm{SiO}_{2}$ composite were dispersed into a $1: 1$ water/ethanol solution $\left(40 \mathrm{~mL}\right.$ ) before adding $\mathrm{NH}_{3} \mathrm{OH} \cdot \mathrm{Cl} / \mathrm{Na}_{2} \mathrm{CO}_{3}$ (dissolved in $5: 1$ water/ ethanol solution) with the following mass ratios 12:4.8 g, 7.5:3 g; and $3: 1.2 \mathrm{~g}$ for $\mathrm{PAN}_{20} / \mathrm{MAA}_{80}, \mathrm{PAN}_{50} / \mathrm{MAA}_{50}$, and $\mathrm{PAN}_{80} / \mathrm{MAA}_{20}$, respectively. The reaction was initiated at $40{ }^{\circ} \mathrm{C}$, for $20 \mathrm{~min}$. In a

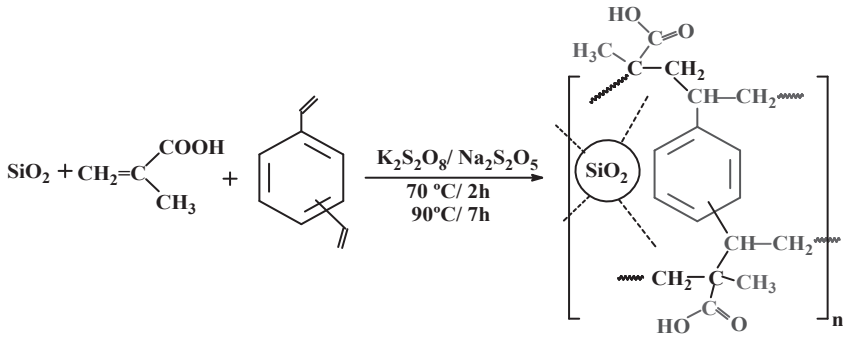

Scheme 2. Synthesis route for the preparation of $\mathrm{PMAA} / \mathrm{SiO}_{2}$.

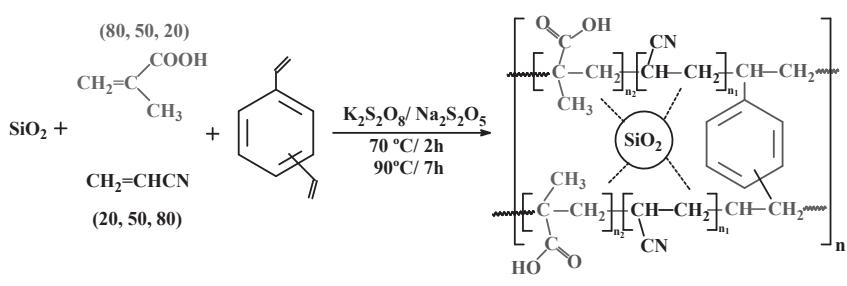

$\mathrm{n}_{1}=20(0.9 g) / \mathrm{n}_{2}=80(3.6 g) ; \mathrm{n}_{1}=50(2.1 \mathrm{~g}) / \mathrm{n}_{2}=50(2.1 \mathrm{~g}) ; \mathrm{n}_{1}=80(3.6 g) / \mathrm{n}_{2}=20(0.9 g)$ for

$\mathrm{PAN}_{20} / \mathrm{MAA}_{80}, \mathrm{PAN}_{50} / \mathrm{MAA}_{50}$, and $\mathrm{PAN}_{80} / \mathrm{MAA}_{20}$, respectively.

Scheme 3. Synthesis route for the preparation of $\mathrm{PAN}_{\mathrm{x}} \mathrm{MAA}_{100-\mathrm{x}} / \mathrm{SiO}_{2}$.

second step, the temperature was raised to $70^{\circ} \mathrm{C}$ (under reflux) and the reaction lasted for $5 \mathrm{~h}$. Sorbents were filtered off and washed several times with hot water and ethanol and finally dried under vacuum at $50{ }^{\circ} \mathrm{C}$ for $12 \mathrm{~h}$. Scheme 4 summarizes the synthesis route (including the generic formula of $\mathrm{PAO}_{\mathrm{x}} \mathrm{MAA}_{100-\mathrm{x}}$ sorbent).

\subsection{Characterization of materials}

The morphology of sorbent particles was observed using a Phenom ProX scanning electron microscope (SEM, Thermo Fisher Scientific, Netherlands). Semi quantitative EDX analysis (integrated in the SEM equipment) was used for characterizing the sorbents before and after metal sorption. Textural investigation was performed using Micromeritics TriStar II (Norcross, GA, USA); the samples were degassed for $13 \mathrm{~h}$ at $100{ }^{\circ} \mathrm{C}$. The specific surface area was determined using BJH methods for BET equation (on both sorption and desorption branches of nitrogen isotherm).

Chemical characterization was investigated using FTIR spectrometry (4000-400 $\mathrm{cm}^{-1}$ ) with an IRTracer-100 (Shimadzu, Tokyo, Japan). Dried samples were grinded and mixed with $\mathrm{KBr}$ and conditioned as $\mathrm{KBr}$ disc, prior to FTIR analysis. XPS analysis was performed using an ESCALAB 250XI + instrument (Thermo Fischer Scientific, Inc., Waltham, MA, USA). Elemental analysis was carried out using a Vario EL cube element analyzer (Elementar Analysensysteme GmbH, Langenselbold, Germany) for quantification of $\mathrm{C}, \mathrm{H}$, and $\mathrm{N}$ elements in the sorbents. Thermal analysis of the sorbents $\left(\mathrm{PAN}_{20} / \mathrm{MAA}_{80}\right.$ and $\left.\mathrm{PAO}_{20} / \mathrm{MAA}_{80}\right) / \mathrm{SiO}_{2}$ were performed using a Netzsch STA 449 F3

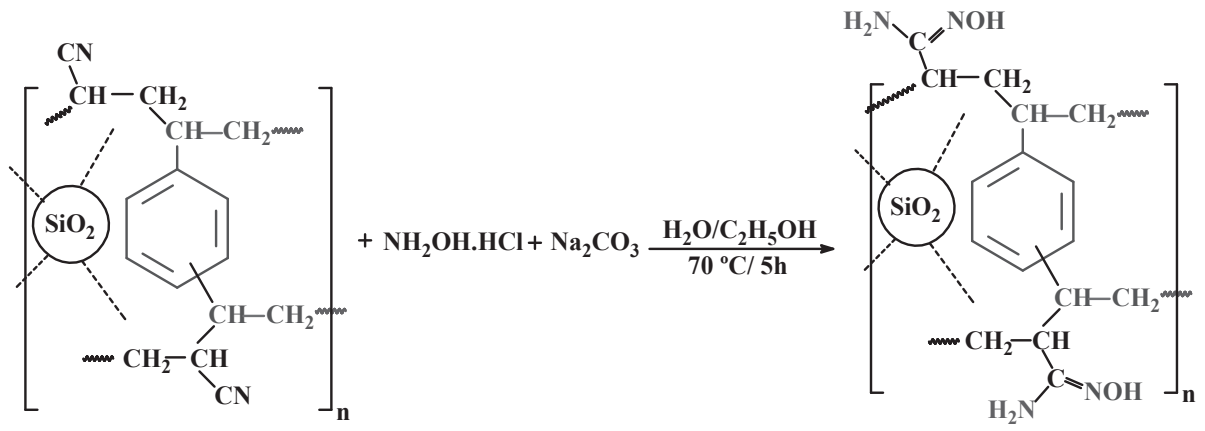

Scheme 1b. Synthesis route for the preparation of $\mathrm{PAO} / \mathrm{SiO}_{2}$. 


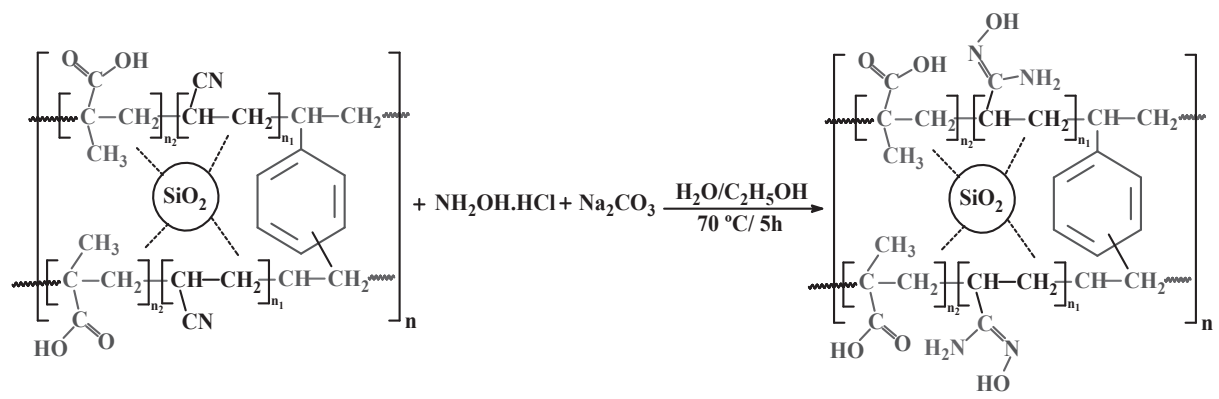

Scheme 4. Synthesis route for the preparation of $\mathrm{PAO}_{\mathrm{x}} \mathrm{MAA}_{100-\mathrm{x}} / \mathrm{SiO}_{2}$.

Jupiter (NETZSCH-Gerätebau GmbH, Selb, Germany) (temperature ramp: $10^{\circ} \mathrm{C} / \mathrm{min}$ ) under nitrogen atmosphere.

The $\mathrm{pH}$-drift method was used for determining the $\mathrm{pH}_{\mathrm{PZC}}$ value [52]. A fixed amount of sorbent (i.e., $100 \mathrm{mg}$ ) was dispersed under agitation for $48 \mathrm{~h}$ in a series of flasks containing $50 \mathrm{~mL}$ of $0.1 \mathrm{M}$ or $1 \mathrm{M}$ $\mathrm{NaCl}$ solutions with initial $\mathrm{pH}\left(\mathrm{pH}_{0}\right)$ adjusted to $1-14$. The final $\mathrm{pH}$ $\left(\mathrm{pH}_{\mathrm{eq}}\right)$ was measured using a Mettler Toledo $\mathrm{pH}$-meter (Colombus, USA) and the $\mathrm{pH}_{\mathrm{PZC}}$ was determined by the value corresponding to: $\mathrm{pH}_{0}=\mathrm{pH}_{\mathrm{eq}}$.

\subsection{Sorption studies}

Most of the experiments were carried out in batch process. A fixed amount of sorbent $(\mathrm{m}, \mathrm{g})$ was mixed with a given volume of solution $(\mathrm{V}$, $\mathrm{L})$, containing strontium $\left(\mathrm{C}_{0}, \mathrm{mmol} \mathrm{Sr} \mathrm{L}^{-1}\right)$ for $48 \mathrm{~h}$. The sorbent dosage (SD, $\mathrm{g} \mathrm{L}^{-1}$ ) was defined as $\mathrm{SD}=\mathrm{m} / \mathrm{V}$. The standard temperature was $22 \pm 2{ }^{\circ} \mathrm{C}$ and the agitation speed was $170 \mathrm{rpm}$. The samples were collected at the end of the experiments, before being filtrated on $1.2 \mu \mathrm{m}$ pore size filter membranes. The residual concentration in the solution $\left(\mathrm{C}_{\mathrm{eq}}, \mathrm{mmol} \mathrm{L} \mathrm{L}^{-1}\right)$ was analyzed using ICP-AES (inductively coupled plasma atomic emission spectrometer, ICPS-7510 Shimadzu, Tokyo, Japan). For kinetic study, samples were collected at fixed contact times, and analyzed (after filtration) for plotting the concentration decay curves. The sorption capacity $\left(\mathrm{q}_{\mathrm{eq}}, \mathrm{mmol} \mathrm{Sr}^{-1}\right.$ ) was determined by the mass balance equation:

$q_{e q}=\frac{\left(C_{0}-C_{e q}\right) \times V}{m}$

For sorption isotherms, the sorbent dosage was set to $0.4 \mathrm{~g} \mathrm{~L}^{-1}$, the initial concentration was varied between 10 and $600 \mathrm{mg} \mathrm{Sr} \mathrm{L}^{-1}$ while the initial $\mathrm{pH}$ of the solution was fixed at $\mathrm{pH}$ 8.0. The suspension was stirred for $48 \mathrm{~h}$. The $\mathrm{pH}$ was not controlled during the sorption but the final $\mathrm{pH}$ value was monitored together with the residual metal concentration. The experiments have been duplicated and the comparison of the duplicates appears as Run \#1 and Run \#2 in the Figures. The experimental conditions have been systematically checked regarding metal precipitation and sorption artifacts on experimental setup.

For desorption studies, the sorbents collected during the sorption kinetics were mixed with $0.5 \mathrm{M} \mathrm{HCl}$ solutions and samples were regularly collected and analyzed for evaluating the released Sr(II) and for plotting the desorption kinetics. For the study of sorbent recycling, the sorption and desorption procedures were used and a rinsing step was processed using demineralized water between each sorption and desorption step. The efficiency of sorption and desorption were compared for five successive cycles.

The presence of other metals may interfere with the removal of $\mathrm{Sr}$ (II). In order to evaluate the impact of alkali and alkali-earth elements (abundant in seawater and/or having similar physicochemical behavior in solution) on $\mathrm{Sr}$ (II) uptake, a series of experiments were performed with equimolar multi-component solutions (i.e., $1.3 \mathrm{mmol} \mathrm{L}^{-1}$ ) at different $\mathrm{pH}$ values (in the range $3-8$ ). The sorbent dosage was set at $0.125 \mathrm{~g} \mathrm{~L}^{-1}$; the suspension was maintained under agitation for $48 \mathrm{~h}$.
After $\mathrm{pH}$ measurement and filtration, the residual concentrations were analyzed by ICP-AES and the sorption capacities were calculated by the mass-balance equation. The distribution ratio $\left(\mathrm{L}^{-1}\right)$ was calculated by:

$D=\frac{q_{e q}}{C_{e q}}$

And the selectivity coefficient $\left(\mathrm{SC}_{\mathrm{Me} 1 / \mathrm{Me} 2}\right)$ was deduced by:

$S C_{M e 1 / M e 2}=\frac{D_{M e 1}}{D_{M e 2}}=\frac{q_{e q, M e 1} \times C_{e q, M e 2}}{C_{e q, M e 1} \times q_{e q, M e 2}}$

Sorption tests were also performed in fixed-bed columns. The sorbent was immobilized in a column (diameter: $5 \mathrm{~mm}$; height: $47 \mathrm{~mm}$ ). The ratio column diameter/particle size being much higher than 12 , the wall effect can be neglected. The column was fed up flow (at flow rates: $0.2,0.4$ and $1 \mathrm{~mL} \mathrm{~min}^{-1}$, corresponding to superficial flow velocities of $0.61,1.22$ and $3.06 \mathrm{~m} \mathrm{~h}^{-1}$ ); $10 \mathrm{~mL}$-samples were collected in series for analysis of outlet concentrations.

The models used for fitting uptake kinetics (i.e., pseudo-first order and pseudo-second order rate equations, PFORE and PSORE; and the Crank equation for resistance to intraparticle diffusion) and sorption isotherms (i.e., Langmuir, Freundlich and Sips equations) are summarized in Tables AM1 and AM2. Non-linear regression analysis was used for the determination of model parameters, while the determination coefficient was determined comparing experimental and simulated data (linear regression analysis). The Akeike information criterion was also applied for comparing the fits of experimental data with selected equations [53]. For the modeling of desorption kinetics (PFORE and PSORE, [54]) and breakthrough curves (Thomas equation [55]), the model equations are reported in the footnotes of relevant tables (see below).

\section{5. $\mathrm{Sr}$ (II) recovery from seawater}

Sorption tests on seawater samples were also performed in batch, using the same experimental procedure as with synthetic solutions: $500 \mathrm{~mL}$ of water (which $\mathrm{pH}$ was controlled to $\mathrm{pH} 4,8$ and 12, using either $\mathrm{HCl}$ or $\mathrm{NaOH}$ solutions) were mixed with $0.1 \mathrm{~g}$ of sorbent for $48 \mathrm{~h}$ (samples were collected at intermediary times for plotting kinetic curves). Semi-quantitative EDX analysis on loaded samples was used for determining the metals to investigate (i.e., $\mathrm{Na}(\mathrm{I}), \mathrm{K}(\mathrm{I}), \mathrm{Mg}(\mathrm{II}), \mathrm{Ca}(\mathrm{II}), \mathrm{Sr}$ (II), B(III), Ru(III) and Mo(VI)).

\section{Results and discussion}

\subsection{Characterization of sorbents}

In the preliminary part of the work, different formulations of bifunctionalized sorbents were compared to the sorption properties of mono-functionalized supports for selecting the best compromise (regarding Sr(II) uptake); results are summarized in the Section 3.2.1. Therefore, the characterization of the material was mainly focused on 
this specific "optimized" sorbent (i.e., $\mathrm{PAO}_{20} \mathrm{MMA}_{80} / \mathrm{SiO}_{2}$ ).

\subsubsection{Morphology and textural properties}

Sp herical silica-based resins have a $\mathrm{p}$ article size in the range $119-132 \mu \mathrm{m}$ (Fig. AM1). The surface is coated by a polymer layer that gives to the sorbent an irregular surface topography. Fig. AM2 shows the BET analysis of raw $\mathrm{SiO}_{2}, \mathrm{PMAA} / \mathrm{SiO}_{2}$ (mono-functionalized) and $\mathrm{PAO}_{20} \mathrm{MAA}_{80} / \mathrm{SiO}_{2}$ (bi-functionalized) beads. While the chemical grafting of silica microparticles usually contributes to strongly decrease the specific surface area (SSA), the pore size and the pore volume [56], in the case of mono- and bi-functionalized silica beads, the textural properties shows contradictory trends. The SSA hardly changes with the successive modifications: from $69.1 \mathrm{~m}^{2} \mathrm{~g}^{-1}\left(\mathrm{SiO}_{2}\right)$ t o $62.4 \mathrm{~m}^{2} \mathrm{~g}^{-1}$ (PMAA/ $\mathrm{SiO}_{2}$ ) and $64.7 \mathrm{~m}^{2} \mathrm{~g}^{-1}$ (bi-functionalized sorbent). Surprisingly, the post-modification (amidoxime grafting) slightly improves the SSA of the sorbent. However, the differences a re $\mathrm{n}$ ot $\mathrm{m}$ arked. The average pore size is of the same order of magnitude for the functionalized materials (around $300 \AA$ ) and little higher than the pore size of raw silica beads (around $230 \AA$ ). The raw support can be considered a mesoporous silica based on the average size of the pores (Fig. AM3). The coating of the silica beads with the polymer layers contribute to fill in the smallest p ores meaning that the average (global) p ore size slightly increases. Unexpectedly, the pore volume also increases with the p rogressive modification of the s up p ortf rom $0.299 \mathrm{c} \mathrm{m}^{3} \mathrm{~g}^{-1}$, to $0.376 \mathrm{~cm}^{3} \mathrm{~g}^{-1}$ for methacrylic acid-grafted silica, and up to $0.399 \mathrm{~cm}^{3}$ $\mathrm{g}^{-1}$ for the bi-functionalized material.

The average pore size largely exceeds the ionic radius of hydrated $\mathrm{Sr}$ (II) species (i.e., 1.26 [57]), meaning that the diffusion of strontium ions will not be strongly hindered by the p orous p rop erties of the composites.

\subsubsection{Elemental analysis}

Table 1 reports the elemental analysis of different sorbents (homoand heteropolymers supported on $\mathrm{SiO}_{2}$ : PAN, PMAA, PAO, at different ratios of substitution). The residue (to $100 \%, \mathrm{w} / \mathrm{w}$ ) is probably associated with $\mathrm{SiO}_{2}$ core (the residue being $\mathrm{Si}$ element): the average value is $31.26 \%$ (with a standard deviation close to $0.85 \%$ ), representing about $53.52 \pm 1.45 \%$ (in weight fraction).

The comparison of the $\mathrm{N}$ content for PAO $v s$. PAN derivatives clearly demonstrates that the amidoximation of nitrile groups is quantitative (the $\mathrm{N}$ content is roughly doubled, consistently with expected reaction (Scheme 1b). The amidoximation is also quantitative for bi-functionalized materials: the $\mathrm{N}$ content $\left(\mathrm{mmol} \mathrm{N} \mathrm{g}^{-1}\right.$ ) is doubled while converting $\mathrm{PAN}_{\mathrm{x}} \mathrm{MMA}_{100-\mathrm{x}} / \mathrm{SiO}_{2}$ into $\mathrm{PAO}_{\mathrm{x}} \mathrm{MMA}_{100-\mathrm{x}} / \mathrm{SiO}_{2}$.

Table AM3 (a-d) shows the semi-quantitative EDX analysis of the surface of composite materials at different stages of the synthesis of sorbents (also including after Sr(II) sorption). Obviously, these semiquantitative analyses must be considered as an indication or a confirmation of $\mathrm{t}$ he $\mathrm{c}$ hemical $\mathrm{m}$ odifications of the ma terials al ong the synthesis procedure for the different compounds. In the SEM analysis, all materials keep the spherical properties of the silica particles with surface coating due to grafting of the hydrocarbon chains. For monofunctional grafted composites, the trends are consistent with suggested synthesis routes. The amidoximation substantially increases the $\mathrm{N}$ atomic fraction $\left(\mathrm{N}_{\mathrm{AF}}\right.$, almost doubled when converting $\mathrm{PAN} / \mathrm{SiO}_{2}$ to $\mathrm{PAO} / \mathrm{SiO}_{2}$ : from 8.06 to $15.37 \%$ ). The rate of substitution is close to $95 \%$. This is associated with a relative increase of $\mathrm{O}$ atomic fraction due to the conversion of $\mathrm{CN}$ into $\mathrm{C}(=\mathrm{NOH}) \mathrm{NH}_{2}$. On the other side, for PMAA/SiO ${ }_{2}$, the grafting of acrylic acid allows drastically increasing $\mathrm{O}$ content (up to 55.52\%); this is directly associated with the potential grafting of two oxygen atoms on carboxylic groups per monomer unit deposited on $\mathrm{SiO}_{2}$ micro-particles. For bi-functional sorbents, using $\mathrm{N}_{\mathrm{AF}}$ as the marker of substitution allows characterizing the quasi-linear increase in substitution rate $\left(\mathrm{AO}_{\text {Subst.Ratio }}\right)$ for $\mathrm{PAN}_{\mathrm{x}} \mathrm{MAA}_{100-\mathrm{x}} / \mathrm{SiO}_{2}$ sorbents $\left(\mathrm{N}_{\mathrm{AF}}=0.07 \times \mathrm{AO}_{\text {Subst.Ratio }}+1.49\right)$ and $\mathrm{PAO}_{\mathrm{x}} \mathrm{MAA}_{100-\mathrm{x}} / \mathrm{SiO}_{2}$ sorbents $\left(\mathrm{N}_{\mathrm{AF}}=0.11 \times \mathrm{AO}_{\text {Subst.Ratio }} \mathrm{R}+2.83\right)$. It is noteworthy that the comparison of $\mathrm{N}_{\mathrm{AF}}$ for nitrilated intermediary materials and amidoximated sorbents demonstrates that the amidoximation rate varies between $83 \%$ and $91 \%$ for bi-functional materials. As expected, when the rate of amidoximation increases the atomic fraction of $\mathrm{O}$ decreases (from 50.5 and $52.9 \%$ to 30.8 and $40.2 \%$ for $\mathrm{PAN}_{\mathrm{x}} \mathrm{MAA}_{100-\mathrm{x}} / \mathrm{SiO}_{2}$ and $\mathrm{PAO}_{\mathrm{x}} \mathrm{MAA}_{100-\mathrm{x}} / \mathrm{SiO}_{2}$, respectively). The conversion of nitrilated monofunctional composite into amidoximated resin is almost quantitative (1.91 times the content of $\mathrm{N}$ in the $\mathrm{PAN} / \mathrm{SiO}_{2}$ material, close to the theoretical factor; i.e., 2). In the case of bi-functional composites, the comparison of $\mathrm{PAN}_{\mathrm{x}} \mathrm{MAA}_{100-\mathrm{x}} / \mathrm{SiO}_{2}$ with $\mathrm{PAO}_{\mathrm{x}} \mathrm{MAA}_{100-\mathrm{x}} / \mathrm{SiO}_{2}$ shows a lower degree of substitution $\left(\mathrm{N}_{\mathrm{AF}}\right.$ increases after amidoximation by a ratio lower than 1.81; (i.e., between 1.61 and 1.81)). The presence of metacrylic acid moieties limits the efficiency of the amidoximation step. This can be explained by two main reasons: (a) the limitations due to steric hindrance, and/or (b) the inhibiting effect associated with the presence of polar carboxylic groups.

\subsubsection{Thermal degradation}

Fig. AM4 shows the thermogravimetric analysis of $\mathrm{PAN}_{20} \mathrm{MAA}_{80} /$ $\mathrm{SiO}_{2}$ and its amidoximated derivative (i.e., $\mathrm{PAO}_{20} \mathrm{MAA}_{80} / \mathrm{SiO}_{2}$ ). The comparison of TGA profiles shows relatively close behaviors. Below 269.1-266. ${ }^{\circ} \mathrm{C}$, superficial water is released from the materials with a weight loss limited to $1.41 \%$ and $2.78 \%$ for $\mathrm{PAN}_{20} \mathrm{MAA}_{80} / \mathrm{SiO}_{2}$ and $\mathrm{PAO}_{20} \mathrm{MAA}_{80} / \mathrm{SiO}_{2}$, respectively. A second weight loss step (representing $5.55 \%$ and $8.26 \%$ for the nitrile and amidoximated materials, respectively) is observed between $269.1-266.5^{\circ} \mathrm{C}$ and 564.9-493. $7^{\circ} \mathrm{C}$. This weight loss may be associated with the degradation of polyacrylonitrile [58,59], amidoxime substituents [60], poly methacrylic acid compound [61], and to the depolymerization of the silica coating. The amidoximation decreases the stability of the composite (highest weight loss and lower temperature of degradation) [60]. Actually, this second step combines different degradation mechanisms associated with the diversity of polymer and functional groups that coat silica particles: several weak shoulders/waves are observed, especially on the TGA profile of nitrile-composite (this is less apparent for amidoximated material). The third step in the thermal degradation corresponds to the degradation of the char, above $493.7{ }^{\circ} \mathrm{C}$ for $\mathrm{PAO}_{20} \mathrm{MAA}_{80} /$ $\mathrm{SiO}_{2}$ and above $564.86^{\circ} \mathrm{C}$ for $\mathrm{PAN}_{20} \mathrm{MAA}_{80} / \mathrm{SiO}_{2}$; the total weight losses correspond to $13.63 \%$ and $7.63 \%$, respectively. This means that the polymer layer coating silica beads is relatively limited: less than $8 \%$ in the case of the intermediary compound (nitrile-composite) and less than $14 \%$ for the amidoximated bi-functionalized composite.

Fig. AM5 compares the DTG (derivative thermogravimetry) profiles for the thermal degradation of the two composites. The nitrile-composite shows a smoothed (poorly resolved) curve with a very broad exothermic band (in the range $100-400^{\circ} \mathrm{C}$ ) without any specific peak. On the opposite hand, after amidoximation the DTG curve shows a little shorter range of temperature (in the range $100-394^{\circ} \mathrm{C}$ ) for the poorly resolved exothermic band, which is completed by twin peaks at $265.14^{\circ} \mathrm{C}$ and $272.55{ }^{\circ} \mathrm{C}$; another small exothermic peak is also detected at $586.48^{\circ} \mathrm{C}$. The cyclization of nitrile was reported at $584^{\circ} \mathrm{C}$ [62]. In the case of silica/PAN hollow nanoparticles and silica/poly

Table 1

Elemental analysis of materials (C, N, H and $\mathrm{O}$ elements, wt $\%$ and $\mathrm{mmol} \mathrm{N} \mathrm{g}^{-1}$ ).

\begin{tabular}{llllll}
\hline Materials & $\mathrm{C}(\%)$ & $\mathrm{N}(\%)$ & $\mathrm{N}\left(\mathrm{mmol} \mathrm{g}^{-1}\right)$ & $\mathrm{H}(\%)$ & $\mathrm{O}(\%)$ \\
\hline PAN & 21.4 & 6.9 & 4.93 & 3.6 & 36.28 \\
PAO & 22.02 & 14.18 & 10.12 & 4.1 & 29.2 \\
PMAA & 21.8 & 0.2 & 0.14 & 4.62 & 40.08 \\
$\mathrm{PAN}_{20} \mathrm{MAA}_{80} / \mathrm{SiO}_{2}$ & 17.6 & 2.18 & 1.56 & 3.71 & 46.31 \\
$\mathrm{PAN}_{50} \mathrm{MAA}_{50} / \mathrm{SiO}_{2}$ & 15.2 & 4.57 & 3.26 & 3.8 & 45.33 \\
$\mathrm{PAN}_{80} \mathrm{MAA}_{20} / \mathrm{SiO}_{2}$ & 13.2 & 5.65 & 4.03 & 3.86 & 45.89 \\
$\mathrm{PAO}_{20} \mathrm{MAA}_{80} / \mathrm{SiO}_{2}$ & 17.9 & 4.71 & 3.36 & 5.01 & 41.18 \\
$\mathrm{PAO}_{50} \mathrm{MAA}_{50} / \mathrm{SiO}_{2}$ & 15.8 & 9.82 & 7.01 & 5.13 & 38.35 \\
$\mathrm{PAO}_{80} \mathrm{MAA}_{20} / \mathrm{SiO}_{2}$ & 14.3 & 10.93 & 7.80 & 5.21 & 38.66 \\
\hline
\end{tabular}


acryclic acid hollow nanogels, the maximum exotherm peak was observed close to $440{ }^{\circ} \mathrm{C}$ for the two comp osites (indifferently of the grafted polymer) [63].

\subsubsection{FTIR analysis}

FTIR spectroscopy was used for characterizing $\mathrm{SiO}_{2}, \mathrm{PAN} / \mathrm{SiO}_{2}$ (Fig. AM6a), PMAA/SiO ${ }_{2}$ (Fig. AM6b), $\mathrm{PAN}_{\mathrm{x}} \mathrm{MAA}_{100-\mathrm{x}} / \mathrm{SiO}_{2}$, and $\mathrm{PAO}_{\mathrm{x}} \mathrm{MAA}_{100-\mathrm{x}} / \mathrm{SiO}_{2}$ (at different c op olymerr atios ( Fig. AM7a,b,c)). The spectra were also characterized for $\mathrm{PAO}_{20} \mathrm{MAA}_{80} / \mathrm{SiO}_{2}$ after $\mathrm{Sr}(\mathrm{II})$ sorption, after metal desorption and after five cycles of sorption desorption. Tables AM4-AM7 report the main characteristics peaks (wavenumbers) and their assignments.

Raw silica shows peaks at $1110 \mathrm{~cm}^{-1}, 806 \mathrm{~cm}^{-1}$, and $474 \mathrm{~cm}^{-1}$, which are assigned to asymmetric stretching and bending vibrations of $\mathrm{Si}-\mathrm{O}-\mathrm{Si}$ bonds [64-66]. The first two peaks are overlapped with $\mathrm{C}-\mathrm{N}$ and $\mathrm{C}-\mathrm{C}$ respectively in polymer-coated $\mathrm{SiO}_{2}[64,67,68]$. The broad peaks at $3442 \mathrm{~cm}^{-1}$ and $1632 \mathrm{~cm}^{-1}$ are assigned to $\mathrm{OH}$ groups in $\mathrm{SiO}_{2}$, associated with water binding at the surface of the solid [65].

After acrylonitrile grafting (in both homo- and hetero-polymer), some specific peaks ap pearincluding nitrile group s $2280-2240 \mathrm{~cm}^{-1}$ $[69,70]$. Carboxylate groups associated to the incorp oration of MAA (both in homo- and hetero-polymers) are identified at $1750-1725 \mathrm{~cm}^{-1}$ [70-72]. Other peaks attributed to carboxylate ester group s are also identified at $1420-1300 \mathrm{~cm}^{-1}$ for $\mathrm{O}-\mathrm{C}=\mathrm{O}$ group stretching vibrations, which overlapped with $\mathrm{C}-\mathrm{N}$ stretching of amide and $-\mathrm{OH}$ bending of amidoxime groups in copolymeric sorbents $[70,73]$. These peaks may overlap with those of silicate and eventually with amide group s of amidoxime [74] (occurring at the second step of the modification in the co-polymer grafting). After the conversion of nitrile to amidoxime, the peak at $2280-2240 \mathrm{~cm}^{-1}$ fully disap pears, showing the effective and complete amidoximation; this is consistent with the conclusions raised from elemental analysis. In addition, the intensity of the broad peak at around $1600-1690 \mathrm{~cm}^{-1}$ increases due to the grafting of the amide groups of amidoxime [75]. The peak at $1050-990 \mathrm{~cm}^{-1}$ is attributed to $\mathrm{N}-\mathrm{O}$ stretching band [66]. In some cases (especially for $\mathrm{SiO}_{2}$ composites), this band may overlap with the broad band of $\mathrm{Si}-\mathrm{O}-\mathrm{Si}$ and/or with $\mathrm{C}-\mathrm{N}$ band that appears at $1090-1020 \mathrm{~cm}^{-1}$ [66].

The sorption of $\mathrm{Sr}(\mathrm{II})$ is characterized by some shifts or broadening of bands. For example, the broad band around $3400-3600 \mathrm{~cm}^{-1}$ tends to enlarge after metal binding; this is probably associated with the interaction of strontium cation with nitrogen and hydroxyl groups (direct and/or changes in their chemical environment). In the case of monofunctionalized PMAA/ $\mathrm{SiO}_{2}$, the most significant changes are observed in the range $1500-1700 \mathrm{~cm}^{-1}$ with the decrease in the intensities of the peaks at $1635 \mathrm{~cm}^{-1}$ and $1680 \mathrm{~cm}^{-1}$, replaced by a peak at $1641 \mathrm{~cm}^{-1}$.
This is directly associated with the interaction of $\mathrm{Sr}$ (II) with carboxylate groups. For $\mathrm{PAO} / \mathrm{SiO}_{2}$, the intensities of the band at $943 \mathrm{~cm}^{-1}(\mathrm{~N}-\mathrm{O}$ stretching) and the shoulder at $569 \mathrm{~cm}^{-1}$ (assigned to $-\mathrm{OH}$ and $\mathrm{C}-\mathrm{H}$ bending vibrations) decrease with metal binding. This may be explained by the interaction of $\mathrm{Sr}(\mathrm{II})$ with amidoxime moiety. The low sorption capacities obtained with mono-functionalized sorbents (see below) may explain the difficulty to identify large changes in the FTIR spectra. Bi-functionalized sorbents (especially for $\mathrm{PAO}_{20} \mathrm{MAA}_{80} / \mathrm{SiO}_{2}$ ) have higher affinity for $\mathrm{Sr}(\mathrm{II})$; therefore, the spectra are also more influenced by the sorption of the metal ions. More specifically, the most representative modifications are reported at:

(a) $2426 \mathrm{~cm}^{-1}$ and satellite peaks around $2360 \mathrm{~cm}^{-1}$ : new small peaks, which could be associated with carbon dioxide at the surface of the sorbent.

(b) $1763 \mathrm{~cm}^{-1}$ peak was shifted to $1718 \mathrm{~cm}^{-1}$; associated with carboxylic groups $\left(\mathrm{C}=\mathrm{O}\right.$ stretching) for $\mathrm{PAO}_{20} \mathrm{MAA}_{80} / \mathrm{SiO}_{2}$ (not detectable for other $\mathrm{PAO}_{\mathrm{x}} \mathrm{MAA}_{100-\mathrm{x}} / \mathrm{SiO}_{2}$ sorbents that have much lower acrylic acid fractions).

(c) $1360-1430 \mathrm{~cm}^{-1}$ : peak widening; the sharp peak at $1383 \mathrm{~cm}^{-1}$ (C$\mathrm{N}$ stretching and $\mathrm{OH}$ bending) is replaced with a broad band of increasing widening when the fraction of amidoxime decreases; in addition, a peak at $1398 \mathrm{~cm}^{-1}$ and two shoulders at $1429 \mathrm{~cm}^{-1}$ and $1358 \mathrm{~cm}^{-1}$ ) also appear after functionalization.

(d) $825 \mathrm{~cm}^{-1}$ : new sharp peak appearing only for bi-functionalized materials (sometimes associated with nitrate compounds [70]).

The changes in the FTIR spectra after Sr(II) sorption confirm the simultaneous contributions of carboxylic groups (from MAA), amine and hydroxyl groups (from amidoxime moiety) in the binding of strontium.

\subsubsection{XPS analysis}

The XPS survey spectra for $\mathrm{PAN}_{20} \mathrm{MAA}_{80} / \mathrm{SiO}_{2}, \mathrm{PAO}_{20} \mathrm{MAA}_{80} / \mathrm{SiO}_{2}$ and $\mathrm{PAO}_{20} \mathrm{MAA}_{80} / \mathrm{SiO}_{2}+\mathrm{Sr}$ are reported on Fig. 1. The XPS spectra confirm the presence of silica core ( $\mathrm{Si} 2 \mathrm{p}$ and $\mathrm{Si} 2 \mathrm{~s}$ ), and polymer markers (C 1s, N 1s and O 1s). The sorption of Sr(II) is confirmed by the appearance of the typical peaks of Sr element ( $\mathrm{Sr} 4 \mathrm{p}, \mathrm{Sr} 3 \mathrm{~d}, \mathrm{Sr} 3 \mathrm{p}$ and $\mathrm{Sr}$ 3s).

Table AM8 shows the high resolution spectra (HRES) of the $\mathrm{C} 1 \mathrm{~s}, \mathrm{O}$ 1s, N 1s and Si 2p signals. Table AM9 reports the HRES of Sr 3d, Sr 4p, $\mathrm{Sr} 3 \mathrm{p}$ and $\mathrm{Sr} 3 \mathrm{~s}$ for $\mathrm{PAO}_{20} \mathrm{MAA}_{8} 0 / \mathrm{SiO}_{2}$ after metal sorption. These tables summarize the assignments, atomic fractions and full-width at half maximum (FWHM) for the deconvolution of the different signals. These analyses contribute to confirm the successful chemical modification of

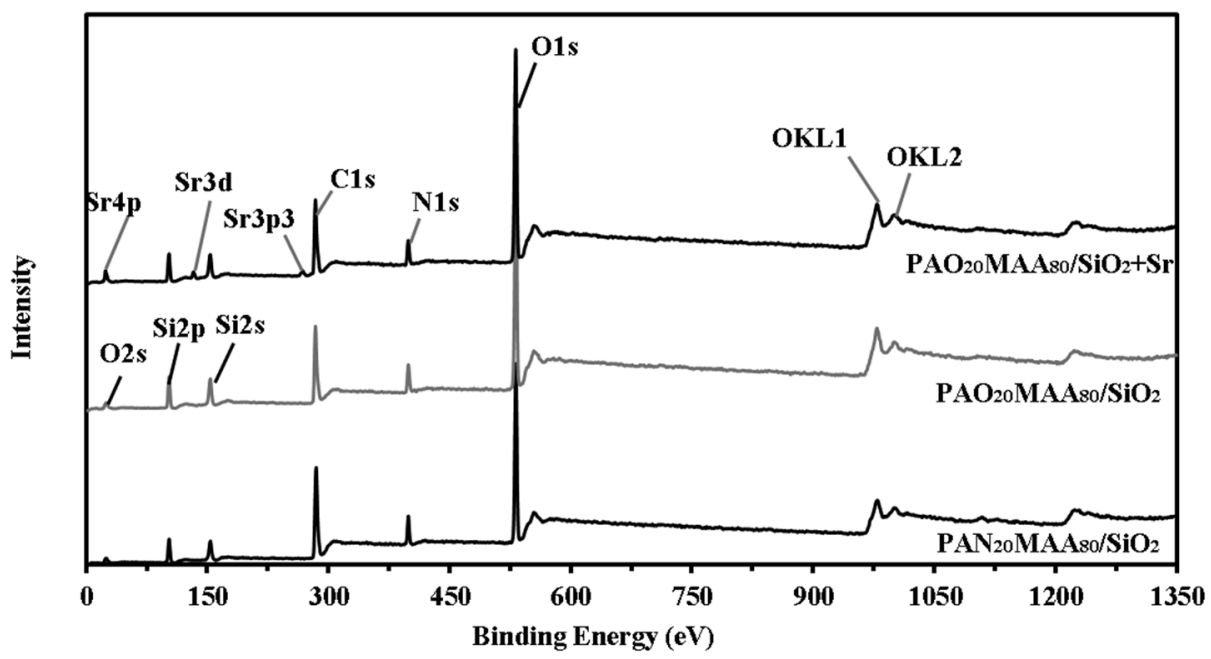

Fig. 1. XPS analysis (survey) of functionalized materials $\left(\mathrm{PAN}_{20} \mathrm{MMA}_{80} / \mathrm{SiO}_{2}, \mathrm{PAO}_{20} \mathrm{MMA} \mathrm{MO}_{80} / \mathrm{SiO}_{2}=\right.$ sorbent, sorbent $+\mathrm{Sr}(\mathrm{II})$ ). 
the support and the interpretation of binding mechanisms.

The composition of the composite bi-functionalized materials offers a wide diversity of signals associated to the different bonds and chemical environments of the $\mathrm{C}, \mathrm{O}$ and $\mathrm{N}$ elements in the different p olymer-coated sorbents. For C 1s signal, the deconvolution of the signal shows the presence of many different $\mathrm{b}$ onds, a ssociated with methacrylic, acrylonitrile and/or amidoxime moieties: $\mathrm{C}-\mathrm{C}$ and $\mathrm{C}-\mathrm{H}$ (or adventitious C) around $284.3 \pm 0.3 \mathrm{eV} ; \mathrm{C}-\mathrm{O}$ or $\mathrm{C}=\mathrm{N}$ at $286.2 \pm 0.4 \mathrm{eV}$ [76]; $\mathrm{O}-\mathrm{C}=\mathrm{O}$ (carboxylic groups) at $287.3 \pm 0.2 \mathrm{eV}$; $\mathrm{C} \equiv \mathrm{N}$ at $288.0 \pm 0.2 \mathrm{eV}$ [77-80]. The composite materials (supported on $\mathrm{SiO}_{2}$ ) contain MAA with either nitrile or amidoxime ending groups; this is confirmed by the disap pearance of $\mathrm{C} \equiv \mathrm{N}$ signal (at $288.13 \mathrm{eV}$ ) when $\mathrm{PAN}_{20} \mathrm{MAA}_{80} / \mathrm{SiO}_{2}$ is amidoximated (together with the appearance of a band corresponding to $\mathrm{C}=\mathrm{NOH}$, at $286.2 \mathrm{eV}$ ). The sorption of $\mathrm{Sr}(\mathrm{II})$ involves a small decrease in the binding energies but also an increase in the atomic fractions of some $\mathrm{C} 1 \mathrm{~s}$ bands, including both $\mathrm{C}$ (carboxyl) and C (amidoxime) groups (from 10.26 to $12.6 \%$ and from 6.13 to $17.97 \%$, respectively).

The chemical modification of the $\mathrm{P} \mathrm{AN}_{20} \mathrm{MAA}_{80} / \mathrm{SiO}_{2}$ is also characterized by the changes observed on $\mathrm{N} 1 \mathrm{~s}$ signal. Ma et al. [76] reported the presence of two bands for $\mathrm{N} 1 \mathrm{~s}$ on polyacrylonitrile fibers at $398.63 \mathrm{eV}$ and $400.60 \mathrm{eV}$ (nitrile group, $\mathrm{C} \equiv \mathrm{N}$, and shake-up line, respectively). After amidoximation, the N 1 s bands appeared at $398.37 \mathrm{eV}$ $(\mathrm{C}=\mathrm{N}-\mathrm{O}$, part of amidoxime $)$ and at $398.82 \mathrm{eV}\left(\mathrm{C}-\mathrm{NH}_{2}\right)$. Li et al. [81] investigated the sorp tion of uranium on MOF functionalized with amidoxime groups and reported three bands at $399.2 \mathrm{eV}, 400.4 \mathrm{eV}$, and $401.45 \mathrm{eV}$ for $\mathrm{C}-\mathrm{NH}_{2}$ or $\mathrm{C}=\mathrm{N}, \mathrm{C}-\mathrm{NOH}$ and $\mathrm{C}-\mathrm{NH}_{2}{ }^{+}$, respectively. This is consistent with the group $\mathrm{s}$ identified o $\mathrm{n}$ r educed $\mathrm{g}$ rap heneoxide grafted with amidoxime groups [82]. With $\mathrm{PAO}_{20} \mathrm{MAA}_{80} / \mathrm{SiO}_{2}$, the two p eaks corresp onding to $\mathrm{N}=\mathrm{C}-\mathrm{OH}$ and $\mathrm{NH}_{2}$ are detected at around $398.9 \mathrm{eV}$ and $400.65 \mathrm{eV}$, respectively; the differences in B Es a re not very marked compared with the nitrile and shake-up lines of precursor. After strontium binding, the BEs of the signals are weakly shifted by $0.15 \mathrm{eV}$ toward higher $\mathrm{BE}$ for $\mathrm{N}=\mathrm{C}-\mathrm{OH}$ (proving the donation of lone pair of electrons from $\mathrm{N}$ through the coordination of $\mathrm{Sr}(\mathrm{II})$ with $\mathrm{N}$ [83]) and lower energy for $\mathrm{NH}_{2}$. Wang et al. [78] investigated uranyl sorption on hydrolyzed amidoximated-PAN fibers and observed that the signal corresponding to $-\mathrm{NH}_{2}$ was slightly shifted after $\mathrm{U}(\mathrm{VI})$ binding; while -NOH bond did not appear to be affected by metal binding and a new peak assigned to $\mathrm{N}-\mathrm{U}$ complexation (around $\mathrm{BE}=404.68 \mathrm{eV}$ ) appeared. Here also, consistently with Wang et al. [78], a new weak band appears at $405.3 \mathrm{eV}$, which is associated with the direct interaction of the metal with $\mathrm{N}$ (from amino groups).
For $\mathrm{O}$ 1s, Wang et al. [78] identified three peaks, on amidoximatedPAN fibers, at $531.18 \mathrm{eV}, 530.34 \mathrm{eV}$ and $529.54 \mathrm{eV}$ corresponding to $-\mathrm{OH},-\mathrm{NO}$ and $-\mathrm{CO}$ groups, respectively. For amidoximated $-\mathrm{MOF}, \mathrm{Li}$ et al. [81] showed substantially higher binding energies for $-\mathrm{OH}, \mathrm{C}=\mathrm{O}$ and $\mathrm{C}-\mathrm{O}$ groups at $531.4 \mathrm{eV}, 532.1 \mathrm{eV}$ and $532.9 \mathrm{eV}$, respectively. Chen et al. [82] synthesized amidoxime-functionalized reduced graphene oxide and they assigned the bands at $531.48 \mathrm{eV}, 532.60 \mathrm{eV}$ and $533.70 \mathrm{eV}$ to $-\mathrm{COO}^{-},>\mathrm{C}=\mathrm{O}$ and $-\mathrm{C}-\mathrm{OH}$ groups, respectively. In the composite sorbents, the presence of $\mathrm{SiO}_{2}$ core introduces a complementary band at around $532.1 \pm 0.2 \mathrm{eV}$. For $\mathrm{PAN}_{20} \mathrm{MAA}_{80} / \mathrm{SiO}_{2}, \mathrm{O}$ element only appears in the silica compartment $(532.27 \mathrm{eV}$; atomic fraction, $\mathrm{AF}$, close to $95 \%)$ and in the methacrylic acid $(530.65 \mathrm{eV})$; however, traces of O-Na bond are also identified at $529.04 \mathrm{eV}$ (residue from synthesis procedure). After amidoximation, the fraction of $\mathrm{O}$ associated with $\mathrm{SiO}_{2}$ core decreases due to the appearance of $-\mathrm{C}\left(\mathrm{NH}_{2}\right)=$ $\mathrm{N}-\mathrm{OH}$ moieties (from 95 to $92 \%$ ), not compensated by the fraction of $\mathrm{C}=\mathrm{NOH}$ that appeared, but by the increasing proportion of $\mathrm{C}=\mathrm{O}$. This may be explained by the conversion of some nitrile groups to carboxylic acid groups by the effect of temperature (and activation technique) and reagents (pH, alkaline conditions) [84]. The sorption of $\mathrm{Sr}(\mathrm{II})$ is followed by the appearance of a new peak at $\mathrm{BE}=528.2 \mathrm{eV}$ (weak signal) and the relative increase in the $\mathrm{AF}$ of $-\mathrm{C}=\mathrm{O}$. This means that $\operatorname{Sr}(\mathrm{II})$ binding may involve some carboxylic groups as mono-dentate ligand and/or combined with amine groups to form multi-dentate complex.

The sorption of $\mathrm{Sr}$ (II) is confirmed on the survey spectrum by signals at binding energies close to $18.42 \mathrm{eV}$ (Sr 4p), $134 \mathrm{eV}$ (Sr 3d) and $277 \mathrm{eV}$ (Sr 3p). The deconvolution of Sr 3d HRES spectrum shows the presence of 2 doublet-peaks (spin-orbital components, corresponding to the $\mathrm{Sr}$ $3 \mathrm{~d}_{5 / 2}$ and $\mathrm{Sr} 3 \mathrm{~d}_{3 / 2}$ spin-orbital splits) for two $\mathrm{Sr}$ chemical environments. The Sr-O bond is the most intense (largest atomic fraction), which is associated with $\mathrm{Sr} 3 \mathrm{~d}_{5 / 2}$ at $132.48 \mathrm{eV}$ and $\mathrm{Sr} 3 \mathrm{~d}_{3 / 2}$ at $134.09 \mathrm{eV}$. Gregurec et al. [85] reported the $\mathrm{Sr} 3 \mathrm{~d}_{5 / 2}$ at $\mathrm{BE}$ close to $133.5 \mathrm{eV}$ in the case of strontium binding by carboxylic groups of poly(acrylic) brushes. Similarly, Wang et al. [27] confirmed the binding of Sr(II) on carboxylic groups of methylacrylic acid/silica composite by the presence of two peaks at $133.55 \mathrm{eV}\left(\mathrm{Sr} 3 \mathrm{~d}_{5 / 2}\right)$ and $135.09 \mathrm{eV}\left(\mathrm{Sr} 3 \mathrm{~d}_{3 / 2}\right)$. In the case of algal/PEI beads functionalized with amidoxime groups, Wei et al. [41] reported $\mathrm{Sr}$ (II) sorption on amidoxime reactive groups with $\mathrm{Sr} 3 \mathrm{~d}_{5 / 2}$ and Sr $3 \mathrm{~d}_{3 / 2}$ bands at lower BEs (i.e., $132.91 \mathrm{eV}$ and $134.59 \mathrm{eV}$, respectively). The coexistence of the four peaks (with very low AF for the peaks at 133.87 and $135.55 \mathrm{eV}$ ) means that amidoxime groups constitute the most active binding groups although carboxylate groups contribute marginally for strontium chelation or stabilization. Other

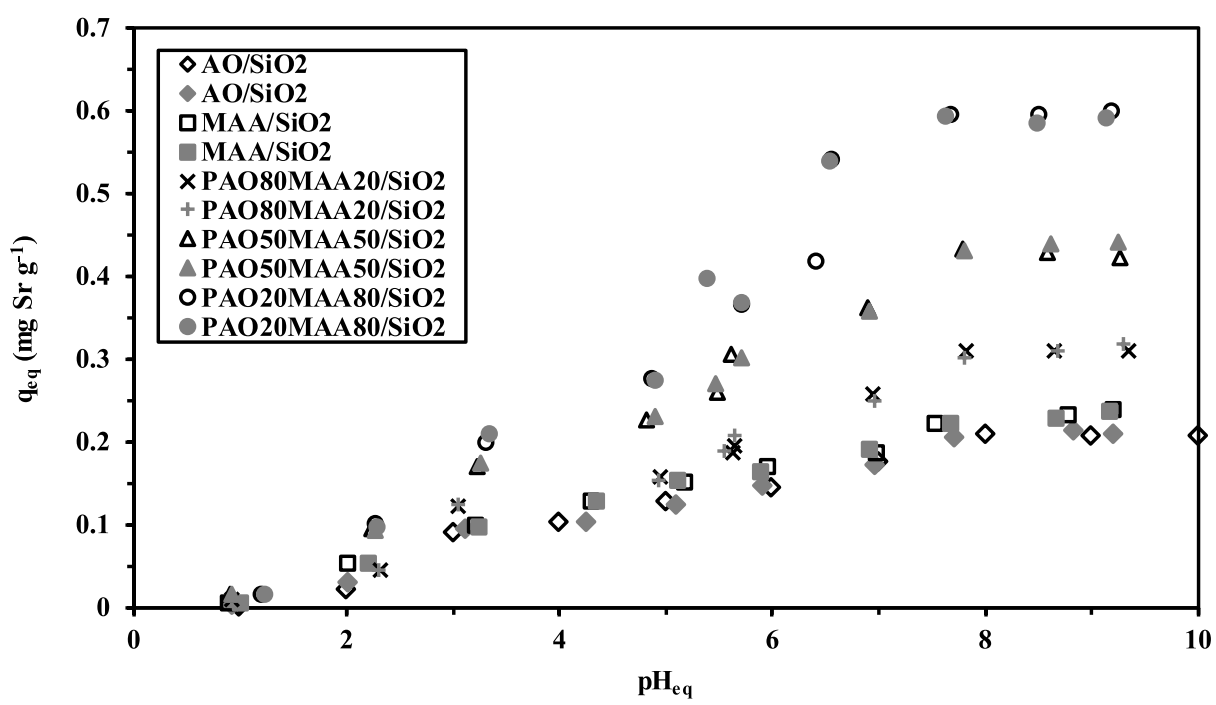

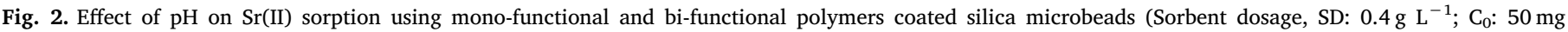

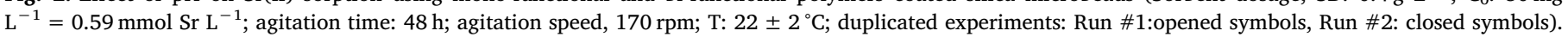


signals for $\mathrm{Sr}$ are observed: $\mathrm{Sr} 4 \mathrm{p}$ (at $18.42 \mathrm{eV}$ ), $\mathrm{Sr} 3 \mathrm{~s}$ (poorly resolved peak, at $355.69 \mathrm{eV}$ ), and Sr 3p (two different spin-orbital splits: Sr 3 $\mathrm{p}_{3 / 2}$ at $268.3 \mathrm{eV}$, and $\mathrm{Sr} 3 \mathrm{p}_{1 / 2}$ at $278.65 \mathrm{eV}$ ). These observations confirm the multi-binding groups of Sr(II) onto the sorbent through two different types of bonds involving probably amine and carboxylate groups from amidoxime and acrylic moieties, resp ectively, and hydroxyl groups from amidoxime and/or acrylic moieties.

\subsubsection{Titration - $p H_{P Z C}$}

The $\mathrm{pH}_{\mathrm{PZC}}$ of the optimized bi-functionalized sorbent is determined by the pH-drift method (Fig. AM8). The average value is close to 6.47 ( \pm 0.02 ), showing the limiting effect of the concentration of the background salt $(0.1 \mathrm{M}$ vs. $1 \mathrm{M} \mathrm{NaCl}$ solution). The co-existence of methacrylic and amidoxime groups brings reactive groups with specific proton exchange properties. For example, the $\mathrm{pK}_{\mathrm{a}}$ values of amidoximebased compounds strongly depend on the substituents but ranges between 3 and 5.3 in most cases [86]. The $p K_{a}$ of methacrylic acid is rep orted close to 4.65 [87]; the p olymerization and the chemical modification of polymethacrylic chain strongly modulate the acid-base properties of functionalized material [88].

Selected functionalized sorbent (i.e., $\mathrm{PAO}_{20} \mathrm{MMA}_{80} / \mathrm{SiO}_{2}$ ) is protonated in acidic solutions; meaning that the sorbent can electrostatically attract anionic species at $\mathrm{pH}$ lower than 6 , and repulse cationic species in acidic conditions ( $\mathrm{pH}$ lower than 3-4). This protonation also opens possibilities for ion-exchange mechanisms at intermediary acidic $\mathrm{pH}$ values (moderate $\mathrm{pH}$ around $\mathrm{pH}$ 5) and metal complexation at neutral $\mathrm{pH}$.

\subsection{Sorption studies}

\subsubsection{Effect of $p H$ and sorbent selection}

Fig. 2 reports the comparison of Sr(II) sorption capacities for monoand bi-functionalized silica comp osites (including variable levels of amidoxime grafting). The experimental series were duplicated and the overlap ping of the curves clearly demonstrates the rep roducibility of sorption performances. At $\mathrm{pH} 1$, the sorption properties for strontium are negligible for the different $\mathrm{m}$ aterials. $\mathrm{T}$ he $\mathrm{s}$ trong $\mathrm{p}$ rotonation of reactive groups limits the capacity of the sorbent to bind strontium, which is present as $\mathrm{Sr}^{2+}$ (about 84.7\%) and $\mathrm{SrNO}_{3}{ }^{+}$(15.3\%). The acid used for $\mathrm{pH}$ control leads to the presence of nitrate anions that may bind to p rotonated reactive group s; the negligible sorp tion capacity means that Sr(II) could not be sorbed as ion pair at the surface of the sorbent. When the $\mathrm{pH}$ increases, the sorption capacity linearly increases up to $\mathrm{pH}$ 7.5-8. The competition of protons decreases and the support p rogressively dep rotonates making possible the binding of strontium cations. $\mathrm{Sr}(\mathrm{II})$ is present as free strontium species at $\mathrm{pH}$ above 4 (with progressive decrease of the fraction of strontium nitrate cation). Above p H 8, the sorp tion stabilizes; similar observations were rep orted by Asgari et al. [37] for Sr(II) sorption on MOF. It is noteworthy that the $\mathrm{pH}$-profiles overlap for mono-functional silica beads (both AO and MAA

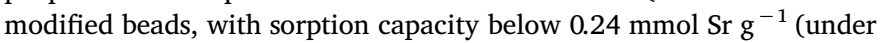
selected experimental conditions). The substitution of $\mathrm{AO}$ on $\mathrm{MAA} / \mathrm{SiO}_{2}$ backbone (i.e., bi-functional sorbents) increases the sorption of $\mathrm{Sr}(\mathrm{II})$ (compared with mono-functional beads). This increase depends on the yield of substitution; actually, highest sorption is obtained at the lowest (tested) rate of substitution (i.e., 20/80 ratio between AO and MAA moieties). The maximum sorp tion cap acities stabilize around $0.31 \mathrm{mmol} \mathrm{Sr} \mathrm{g}{ }^{-1}$ for $\mathrm{PAO}_{80} \mathrm{MAA}_{20} / \mathrm{SiO}_{2}, 0.44 \mathrm{mmol} \mathrm{Sr} \mathrm{g}{ }^{-1}$ for $\mathrm{PAO}_{50} \mathrm{MAA}_{50} / \mathrm{SiO}_{2}$, and up to $0.59 \mathrm{mmol} \mathrm{Sr} \mathrm{g}{ }^{-1}$ for $\mathrm{PAO}_{20} \mathrm{MAA}_{80} / \mathrm{SiO}_{2}$. Fig. AM9 shows the correlation between the rate of $\mathrm{AO}$ substitution and the maximum sorption capacity (obtained on the stabilization plateau reached above $\mathrm{pH}$ 7.5).

Table AM3 (a-d) compares the semi-quantitative EDX surface analysis of the different sorbents after Sr(II) sorption. This data confirm the observations from Fig. 2: the sorption of Sr(II) decreases with the excessive amidoximation of intermediary $\mathrm{PAN}_{\mathrm{x}} \mathrm{MAA}_{100-\mathrm{x}} / \mathrm{SiO}_{2}$ composite.
However, compared with $\mathrm{PMAA} / \mathrm{SiO}_{2}$, the presence of amidoxime groups increases the binding of $\mathrm{Sr}\left(\mathrm{II}\right.$ ): $\mathrm{Sr}_{\mathrm{AF}}$ increases from 1.59 (for PMAA/ $\mathrm{SiO}_{2}$ ) to 2.19 (for $\mathrm{PAO}_{20} \mathrm{MAA}_{80} / \mathrm{SiO}_{2}$ ), while a larger substitution rate decreases metal uptake. These observations are consistent with Fig. AM9.

Figure AM10 shows the $\log _{10}$-plots of the distribution ratio $\left(\mathrm{D}=\mathrm{q}_{\mathrm{eq}} / \mathrm{C}_{\mathrm{eq}}, \mathrm{L} \mathrm{g}^{-1}\right) v s \mathrm{pH}_{\mathrm{eq}}$. The insert focuses on the linear section of these curves (registered between $\mathrm{pH} 2$ and 8). The slopes vary between 0.109 and 0.176 . In ion-exchange reactions, the slope is frequently associated with the stoichiometric ratio for proton exchange at the surface of the sorbent and metal ions. In present cases, the slope analysis cannot be correlated to appropriate ion-exchange ratio.

The $\mathrm{pH}$ frequently changes during the sorption process and it is important correlating sorption properties with these $\mathrm{pH}$ variations. In the case of mono- and bi-functionalized silica sorbents, the $\mathrm{pH}$ variation is relatively limited (by less than $0.5 \mathrm{pH}$ unit) (Fig. AM11): the $\mathrm{pH}$ slightly increases at $\mathrm{pH} 4$ and 5 and tends to slightly decreases at $\mathrm{pH}$ above 6. This is consistent with the study of $\mathrm{pH}_{\mathrm{PZC}}$ (around 6.5, for $\mathrm{PAO}_{20} \mathrm{MAA}_{80} / \mathrm{SiO}_{2}$ ), although the $\mathrm{pH}$ variations are much less marked in the presence of strontium.

Based on these results, further experiments are performed at $\mathrm{pH}_{0} 8$ (corresponding to $\mathrm{pH}_{\mathrm{eq}}$ around 7.4-7.6). The optimum sorption being obtained with the lowest rate of AO substitution, further experiments are also carried out with this specific optimized sorbent (i.e., $\mathrm{PAO}_{20} \mathrm{MAA}_{80} / \mathrm{SiO}_{2}$ ). Alexandratos et al. [46] discussed the interest of bi-functionalization of polyacrylonitrile fibers (using amidoxime and amine groups) for improving the sorption of U(VI). They recognized several effects for this double functionalization: (a) the amine groups (preferentially diethylenetriamine, DETA) introduce additional sorption sites for U(VI) binding, and (b) the interaction of DETA with AO (though hydrogen bonding) contributes to improve the dissociation of the acidic $\mathrm{N}-\mathrm{O}-\mathrm{H}$ group. In the case of bi-functional (carbonyl and phosphoryl groups) resins, Alexandratos and Smith reported the counter-current effects of the bi-functionalization through intraligand cooperation and intraligand hydrogen bonding mechanisms. In the case of uranyl sorption (as carbonate anionic species), the synergistic effect of positive charge and amidoxime coordination have been demonstrated to explain the high efficiency of bi-functional resins [47]. Piechowicz et al. [39] explained the remarkable sorption of uranyl from seawater onto a bi-functional polymer by the simultaneous weak coordination of uranyl with chelating carboxylates and monodentate binding by amidoxime groups. Bi-functionalization (amidoxime and sulfur compounds) was also discussed by Qu et al. [48] for improving the selective removal of $\mathrm{Hg}$ (II) from multi-component solutions. The literature is much less abundant concerning the enhancement of $\operatorname{Sr}(\mathrm{II})$ sorption properties using bi-functionalized sorbents. El-Naggar et al. [89] described the enhancement of sorption properties for divalent cations (including $\mathrm{Sr}(\mathrm{II})$ ) while modifying a resin by simultaneously grafting different reactive groups (P-based ligands). The multi-group cooperation, called supported ligand synergistic interaction, depends on the target metal and the acidity of the solution. Recently, Younis et al. [43] reported a substantial increase in $\mathrm{Sr}$ (II) (and Ca(II)) sorption by simultaneous grafting of sulfonic and carboxylic groups on a polymer backbone (styrene butadiene/acrylonitrile resin) for metal recovery from highly saline oilfield wastewater.

\subsubsection{Uptake kinetics}

The uptake kinetics can be controlled by the resistance to bulk diffusion, to film diffusion and to intraparticle diffusion, in addition to the proper reaction rate of sorption. Providing a sufficient agitation to prevent particle settling and heterogeneous distribution of the solute in the solution and to minimize the resistance to film diffusion allows neglecting the first two diffusion criteria. For film diffusion, the resistance to mass transfer is usually limited to the first minutes of contact. Therefore, the resistance to intraparticle diffusion (RIDE, the socalled Crank equation) is more appropriate for the modeling of kinetic 
profiles on a wider time $r$ ange (Table A M1, s ee A dditional Material Section). The sorption process can be modeled using, by analogy with homogeneous reactions, the pseudo-first order rate equation (PFORE) and/or the pseudo-second order rate equation (PSORE) (Table AM1). Fig. 3 compares the fits of experimental data for $\mathrm{Sr}$ (II) uptake at three different initial metal concentrations using $\mathrm{P} \mathrm{AO}_{20} \mathrm{MAA}_{80} / \mathrm{SiO}_{2}$ and the three models. The solid lines corresp ond to fitted $\mathrm{c}$ urves $\mathrm{w}$ ith the parameters summarized in Table 2. Fig. AM12 shows an example of rep roducibility test for uptake kinetics. The sorption of $\mathrm{Sr}$ (II) is relatively fast: 25-60 min of contact are necessary for reaching equilibrium, dep ending on metal concentration. More than $90 \%$ of total sorption occurs within the first $25 \mathrm{~min}$ of contact. The small size of the sorbent (around $125 \mu \mathrm{m}$ ), the large pore size of the composites and the thin polymer layers (which controlled the diffusion thickness to be passed through) may explain the relatively fast sorption kinetics. The hydrated ionic size of strontium is close to $1.26 \AA$ [57]; this means two orders of magnitude lower than the average pore size of the sorbent.

The superimposition of the curves with the three models shows the difficulty to di scriminate be tween th e di fferent mod els, at lea st at higher metal concentrations. The curve obtained at the lowest Sr(II) concentration (i.e., $\mathrm{C}_{0}$ : $0.604 \mathrm{mmol} \mathrm{Sr} \mathrm{L}^{-1}$ ) shows a greater inaccuracy in the time range 15-30 min (corresponding to the highest curvature). In this case, the best fit was obtained with the PFORE; this is confirmed by both the determination coefficient (i.e., $\mathrm{R}^{2}$ ) and the value of the sorption capacity at equilibrium ( $\mathrm{q}_{\mathrm{eq}, 1}$, calculated value from PFORE) closer to the exp erimental value ( $\mathrm{q}_{\mathrm{eq}, \exp }$ ) than $\mathrm{q}_{\mathrm{eq}, 2}$ (calculated from PSORE). The PFORE is frequently associated with physical sorption while the PSORE counts on chemical interactions. The indistinct fitting trends cannot help in discriminating between the two types of interaction modes. The complementary analysis of fitting parameters with the Akaike information criterion (AIC) shows that at low metal concentration the curve is better fitted by the P FORE w hile a t higher concentration the RIDE better simulates the kinetic profiles. The values of apparent rate coefficients $\left(\mathrm{k}_{1}\right.$ and $\mathrm{k}_{2}$ ) slightly vary with metal concentration: in the range 8.9-16.7 $\times 10^{-2} \mathrm{~min}^{-1}$ for PFORE and between 19.3 and $12.2 \times 10^{-2} \mathrm{~L} \mathrm{mmol}^{-1} \mathrm{~min}^{-1}$ for PSORE. At higher concentrations (i.e., 2.37 and $3.57 \mathrm{mmol} \mathrm{Sr}^{-1}$ ), the RIDE fits well the kinetic p rofiles. The e ffective di ffusivity coe fficient $\left(D_{\text {eff }}\right)$ varies between $6.8 \times 10^{-11} \mathrm{~m}^{2} \mathrm{~min}^{-1}$ and $11.7 \times 10^{-11} \mathrm{~m}^{2} \mathrm{~min}^{-1}$; These values are about three orders of magnitude lower than the self-diffusivity of $\mathrm{Sr}$ (II) in water (i.e., $4.75 \times 10^{-8} \mathrm{~m}^{2} \mathrm{~min}^{-1}$, [90]). This is a confirmation that the resistance to intraparticle diffusion plays a role in the control of the up take kinetics. These values are about one order of magnitude lower than the values rep orted for diffusivity of $\mathrm{Sr}$ (II) in sorbent based on titanium phosphate (i.e., $6 \times 10^{-10} \mathrm{~m}^{2} \mathrm{~min}^{-1}$ ) [91] but several orders of magnitude higher than the effective diffusivity of Sr(II) into straw-derived char $\left(5.4 \times 10^{-14} \mathrm{~m}^{2} \mathrm{~min}^{-1}\right)$ [92]. For macroporous resin, $\mathrm{Sr}(\mathrm{II})$ diffusivity was evaluated close to $1.2 \times 10^{-8} \mathrm{~m}^{2}$ $\mathrm{min}^{-1}$ [93]. In the case of Dowex resins, Boyd and Soldano [94] identified the contribution of crosslinking ratio to the control of diffusion p roperties (in the range: $1.37-2.03 \times 10^{-9} \mathrm{~m}^{2} \mathrm{~min}^{-1}$ ); similar value was rep orted for Dowex $50 \mathrm{~W}$-X8 resin (i.e., $1.17 \times 10^{-9} \mathrm{~m}^{2}$ $\mathrm{min}^{-1}$ ) [95]. These different $\mathrm{d}$ ata $\mathrm{c}$ onfirm th at the ma ss transfer p rop erties of the bi-functionalized $\mathrm{SiO}_{2}$ comp osite are roughly comparable to those reported for conventional resins.

\subsubsection{Sorption isotherms}

The distribution of the solute between the liquid and solid phase for increasing concentrations is described by sorp tion isotherms. The sorption isotherms can be fitted by different models such as Langmuir equation (mechanistic model) and Freundlich or Sips equations (emp irical models). Fig. 4 comp ares the modeling of Sr(II) sorption isotherm at $\mathrm{pH}_{0} 8$ for $\mathrm{PAO}_{20} \mathrm{MAA}_{80} / \mathrm{SiO}_{2}$ sorbent. The superimposition of the two duplicated series confirm the reproducibility of sorption performance on selected sorbent. The general shape of the curve is characterized by a progressive increase of sorption capacity followed by an asymptotic plateau (for equilibrium concentration above $4 \mathrm{mmol} \mathrm{Sr}$ $\mathrm{g}^{-1}$ ). This asymptotic trend is not consistent with the power-type function represented by the Freundlich equation: this is consistent with Table 3 that summarizes the fitted parameters. The initial slope of the curve is representative of the affinity of $\mathrm{PAO}_{20} \mathrm{MAA}_{80} / \mathrm{SiO}_{2}$ for $\mathrm{Sr}(\mathrm{II})$. Actually, this initial slope is not steep; showing that appreciable sorption capacities require high metal concentration: the removal of $\mathrm{Sr}(\mathrm{II})$ traces will require high sorbent dosage for achieving complete metal recovery. The initial slope corresponds to the coefficient $\mathrm{q}_{\mathrm{m}, \mathrm{L}} \times \mathrm{b}_{\mathrm{L}}$ (L $\mathrm{g}^{-1}$ ); in the present case, this term, analogous of distribution ratio, tends to 2.14 and $2.29 \mathrm{~L} \mathrm{~g}^{-1}$ for series \#1 and \#2, respectively. The comparison of the fits with experimental data show that the Freundlich and the Sips equations tend to overestimate the sorption capacities at the saturation of the sorbent, contrary to the Langmuir equation. The insert shows the initial section of the curve where the Langmuir equation underestimates sorption capacities while the Freundlich underestimates experimental data; the Sips equation fits better the profile
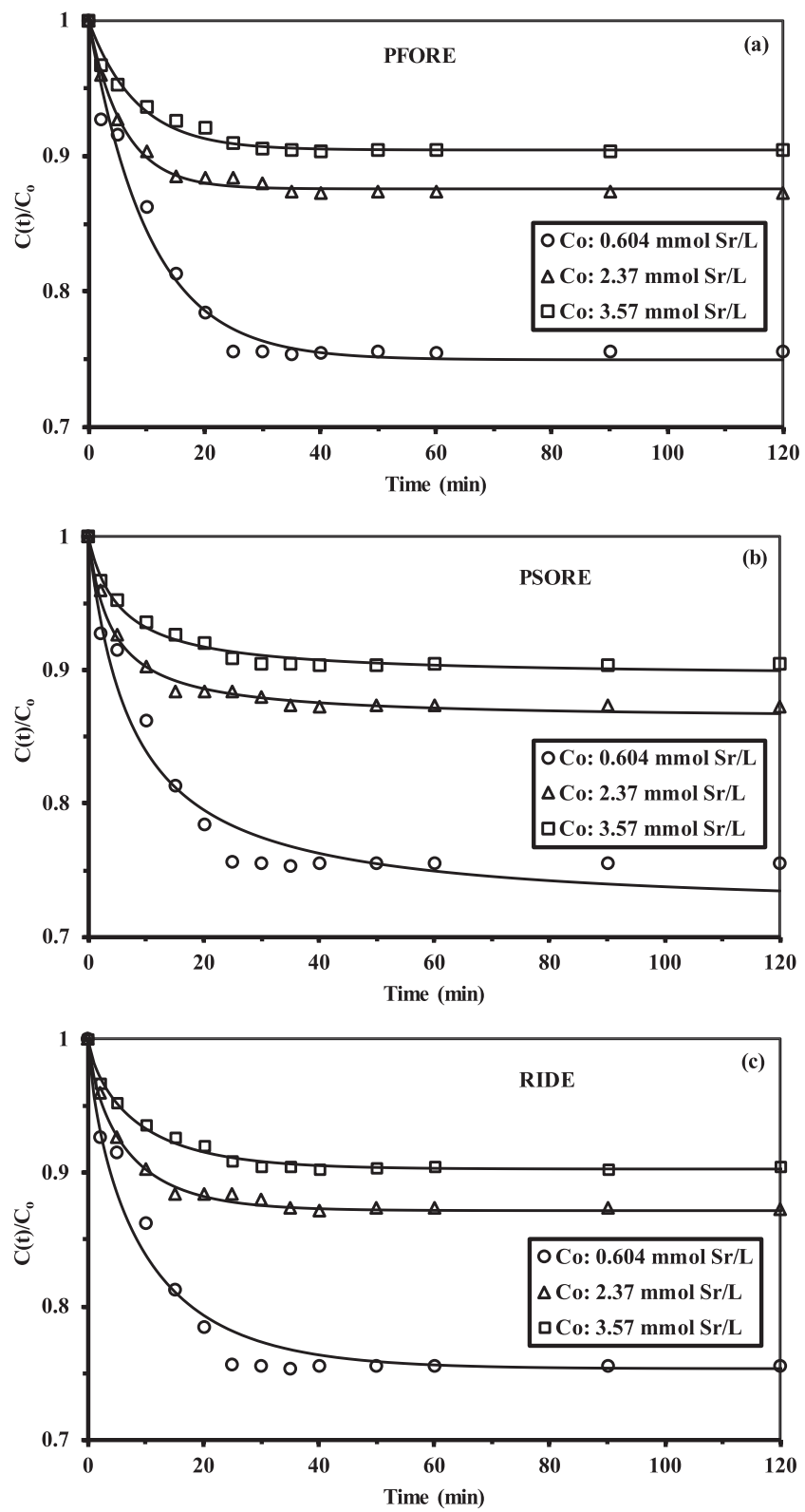

Fig. 3. $\mathrm{Sr}(\mathrm{II})$ uptake kinetics using $\mathrm{PAO}_{20} \mathrm{MAA} \mathrm{A}_{80} / \mathrm{SiO}_{2}$ for different initial concentrations - Modeling with the PFORE(a), the PSORE (b) and the RIDE (c) $\left(\mathrm{pH}_{0}: 8 ; \mathrm{pH}_{\mathrm{eq}}: 7.59-7.51 ; \mathrm{SD}: 0.25 \mathrm{~g} \mathrm{~L}^{-1}\right.$; agitation speed: $170 \mathrm{rpm}$; $\mathrm{T}$ : $\left.22 \pm 2{ }^{\circ} \mathrm{C}\right)$. 
Table 2

Parameters of kinetic models for Sr(II) sorption using $\mathrm{PAO}_{20} \mathrm{MAA}_{80} / \mathrm{SiO}_{2}$.

\begin{tabular}{|c|c|c|c|c|c|}
\hline \multirow[b]{3}{*}{ Model } & \multirow[b]{3}{*}{ Parameter } & \multicolumn{4}{|c|}{$\mathrm{C}_{0}\left(\mathrm{mmol} \mathrm{Sr} \mathrm{L}{ }^{-1}\right)$} \\
\hline & & \multicolumn{2}{|l|}{0.6} & \multirow[t]{2}{*}{2.37} & \multirow[t]{2}{*}{3.57} \\
\hline & & Run \#1 & Run \#2 & & \\
\hline Experimental & $\mathrm{q}_{\mathrm{eq}}\left(\mathrm{mmol} \mathrm{U} \mathrm{g}^{-1}\right)$ & 0.591 & 0.592 & 1.21 & 1.36 \\
\hline \multirow[t]{4}{*}{ PFORE } & $\mathrm{q}_{\mathrm{eq}, 1}\left(\mathrm{mmol} \mathrm{U} \mathrm{g}^{-1}\right)$ & 0.608 & 0.604 & 1.18 & 1.36 \\
\hline & $\mathrm{k}_{1} \times 10^{2}\left(\min ^{-1}\right)$ & 8.88 & 9.59 & 16.7 & 12.1 \\
\hline & $\mathrm{R}^{2}$ & 0.982 & 0.981 & 0.993 & 0.979 \\
\hline & $\mathrm{AIC}^{*}$ & -127.6 & -132.3 & -159.6 & -157.8 \\
\hline \multirow[t]{4}{*}{ PSORE } & $\mathrm{q}_{\mathrm{eq}, 2}\left(\mathrm{mmol} \mathrm{U} \mathrm{g}{ }^{-1}\right)$ & 0.703 & 0.683 & 1.30 & 1.50 \\
\hline & $\begin{array}{l}\mathrm{k}_{2} \times 10^{2}\left(\mathrm{~L} \mathrm{mmol}^{-1}\right. \\
\left.\mathrm{min}^{-1}\right)\end{array}$ & 15.5 & 19.3 & 18.9 & 12.2 \\
\hline & $\mathrm{R}^{2}$ & 0.947 & 0.958 & 0.992 & 0.983 \\
\hline & AIC* & -110.4 & -114.4 & -154.3 & -156.2 \\
\hline \multirow[t]{3}{*}{ RIDE } & $\mathrm{D}_{\mathrm{e}} \times 10^{11}\left(\mathrm{~m}^{2} \mathrm{~min}^{-1}\right)$ & 6.79 & 7.30 & 11.69 & 9.30 \\
\hline & $\mathrm{R}^{2}$ & 0.958 & 0.971 & 0.996 & 0.991 \\
\hline & $\mathrm{AIC}^{*}$ & -119.5 & -123.0 & -167.2 & -164.8 \\
\hline
\end{tabular}

AIC (calculated on $\mathrm{C}(\mathrm{t}) / \mathrm{C}_{0}$ values). $\mathrm{D}_{0}$ (strontium): $4.75 \times 10^{-8} \mathrm{~m}^{2} \mathrm{~min}^{-1}$.

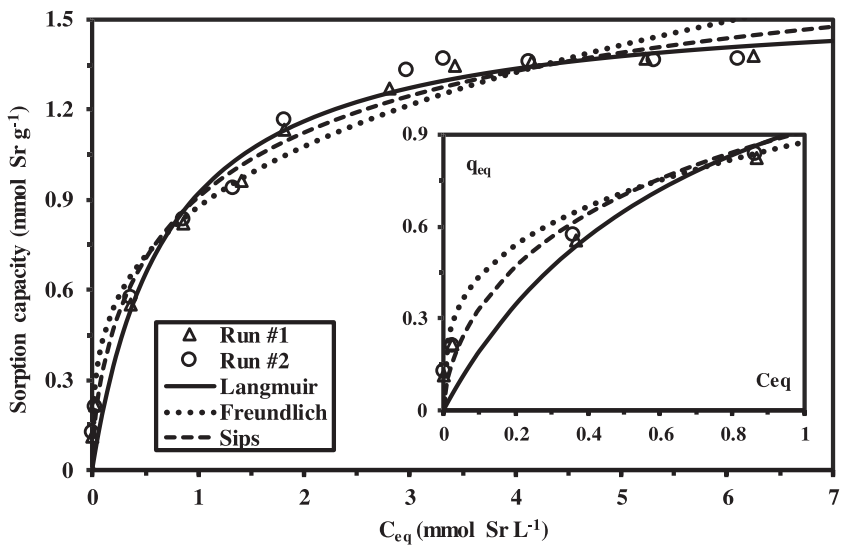

Fig. 4. $\mathrm{Sr}(\mathrm{II})$ sorption isotherm using $\mathrm{PAO}_{20} \mathrm{MAA}_{80} / \mathrm{SiO}_{2}-$ Modeling with Langmuir, Freundlich and Sips equations $\left(\mathrm{C}_{0}: 4-600 \mathrm{mg} \mathrm{Sr} \mathrm{L}{ }^{-1}=7.71-7.49\right.$; SD: $0.4 \mathrm{~g} \mathrm{~L}^{-1}$; agitation time: $48 \mathrm{~h}$; agitation speed: $170 \mathrm{rpm}$; $\mathrm{T}: 22 \pm 2{ }^{\circ} \mathrm{C}$ ).

Table 3

Parameters of models for $\mathrm{Sr}(\mathrm{II})$ sorption isotherms using $\mathrm{PAO}_{20} \mathrm{MAA}_{80} / \mathrm{SiO}_{2}$.

\begin{tabular}{lllll}
\hline Model & Parameter & Run \#1 & Run \#2 & Combined \\
\hline Experimental & $\mathrm{q}_{\mathrm{m}}\left(\mathrm{mmol} \mathrm{U} \mathrm{g}^{-1}\right)$ & 1.379 & 1.371 & 1.379 \\
Langmuir & $\mathrm{q}_{\mathrm{m}, \mathrm{L}}\left(\mathrm{mmol} \mathrm{U} \mathrm{g}^{-1}\right)$ & 1.575 & 1.573 & 1.574 \\
& $\mathrm{~b}_{\mathrm{L}}\left(\mathrm{L} \mathrm{mmol}^{-1}\right)$ & 1.356 & 1.454 & 1.405 \\
& $\mathrm{R}^{2}$ & 0.990 & 0.983 & 0.988 \\
Freundlich & $\mathrm{AIC}$ & -53.6 & -50.3 & -53.4 \\
& $\mathrm{k}_{\mathrm{F}}$ & 0.869 & 0.881 & 0.875 \\
& $\mathrm{n}_{\mathrm{F}}$ & 3.349 & 3.361 & 0.875 \\
& $\mathrm{R}^{2}$ & 0.971 & 0.959 & 0.968 \\
Sips & $\mathrm{AIC}$ & -50.9 & -47.0 & -50.8 \\
& $\mathrm{q}_{\mathrm{m}, \mathrm{S}}\left(\mathrm{mmol} \mathrm{U} \mathrm{g}^{-1}\right)$ & 1.981 & 2.060 & 2.021 \\
& $\mathrm{~b}_{\mathrm{S}}(\mathrm{L} \mathrm{mmol}$ & & 0.807 & 0.817 \\
& $\mathrm{n}_{\mathrm{S}}$ & 0.829 & 0.807 & 1.617 \\
& $\mathrm{R}^{2}$ & 1.556 & 1.675 & 0.984 \\
& $\mathrm{AIC}$ & 0.988 & 0.977 & -52.8 \\
\hline
\end{tabular}

AIC (calculated on $\mathrm{q}_{\mathrm{eq}}$ values).

at low residual metal concentration. Table 3 confirms that the Langmuir equation fits slightly better experimental curve than the alternative models. However, the calculated sorption capacity at saturation of the monolayer (i.e., $\mathrm{q}_{\mathrm{m}, \mathrm{L}}$ ) significantly overestimates the maximum sorp-

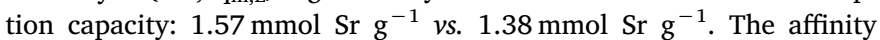
coefficient (i.e., $\mathrm{b}_{\mathrm{L}}$ ) stands around $1.41 \mathrm{~L} \mathrm{mmol}^{-1}$. The AIC calculation normalizes the fitting of experimental data for the different models in
Table 4

Comparison of $\mathrm{Sr}$ (II) sorption properties of $\mathrm{PAO}_{20} \mathrm{MAA}_{80} / \mathrm{SiO}_{2}$ with alternative sorbents (optimum pH, equilibrium time, Langmuir parameters).

\begin{tabular}{|c|c|c|c|c|c|}
\hline Sorbent & $\mathrm{pH}$ & Time & $\mathrm{q}_{\mathrm{m}, \mathrm{L}}$ & $\mathrm{b}_{\mathrm{L}}$ & Ref. \\
\hline Clay & 3 & 300 & 0.034 & 294 & [99] \\
\hline Almond green hull & 6 & 3 & 1.33 & 0.421 & {$[100]$} \\
\hline $\begin{array}{l}\text { Oxidized multiwall carbon } \\
\text { nanotubes }\end{array}$ & 7 & 1440 & 0.076 & 53.3 & [10] \\
\hline Moss & 6 & 240 & 0.149 & 5 & {$[16]$} \\
\hline Magnetic chitosan beads & 8.2 & 360 & 0.132 & - & {$[101]$} \\
\hline Zr-Sb oxide/PAN composite & 4.74 & 270 & 0.498 & 73.6 & {$[102]$} \\
\hline $\begin{array}{l}\text { Mixed Ni-K ferrocyanide/hydrated } \\
\quad \mathrm{TiO}_{2}\end{array}$ & 7.8 & 180 & 1.598 & 0.366 & {$[31]$} \\
\hline Co-aminophosphonic chitosan & 6 & 60 & 0.0389 & 78.0 & [103] \\
\hline Saccharomyces cerevisiae & $3-4$ & 2000 & 0.427 & 3.08 & [14] \\
\hline Nd-BTC-MOF & 8 & $60-90$ & 0.667 & 0.876 & [37] \\
\hline Melamine-styrene resin & 8 & 240 & 1.63 & 3.33 & {$[104]$} \\
\hline Magnetic zeolite nanocomposite & 6 & $20-30$ & 1.01 & 1.31 & {$[5]$} \\
\hline $\begin{array}{l}\text { T-46 (sulfonic)/A-33 (quaternary) } \\
\text { mixed resins }\end{array}$ & 7 & 30 & 0.109 & 8.39 & [105] \\
\hline Graphene oxide & 6 & 1440 & 1.573 & 0.876 & {$[106]$} \\
\hline Amidoximated algal/PEI beads & 6 & $60-90$ & 2.36 & 2.01 & {$[107]$} \\
\hline Carboxyl-functionalized $\mathrm{SiO}_{2}$ & 10 & 30 & 0.913 & 1822 & {$[27]$} \\
\hline Zeolite & 7.9 & 10 & 0.272 & 10.9 & {$[108]$} \\
\hline CHA-type zeolite & 7 & 60 & 0.132 & - & [109] \\
\hline $\mathrm{PAO}_{20} \mathrm{MAA}_{80} / \mathrm{SiO}_{2}$ & 8 & $40-60$ & 1.57 & 1.41 & This work \\
\hline
\end{tabular}

Time: min; $\mathrm{q}_{\mathrm{m}, \mathrm{L}}: \mathrm{mmol} \mathrm{Sr} \mathrm{L}^{-1} ; \mathrm{b}_{\mathrm{L}}: \mathrm{L} \mathrm{mmol}^{-1}$.

function of the number of adjustable parameters. The Sips model that includes a third-adjustable parameter (compared with the two other models) could improve the quality of the fit; this is not the case, as shown by both the determination coefficients and the AIC values.

Table 4 compares the sorption properties of selected composite with alternative sorbents reported in literature. Combining the kinetic and equilibrium criteria, the bi-functionalized $\mathrm{SiO}_{2}$ sorbent appears among the most efficient sorbents for $\mathrm{Sr}(\mathrm{II})$. It is noteworthy that, based on TGA analysis, the polymer content represents about $13.6 \%$ of the composite; this means that the functionalized polymer layer is highly

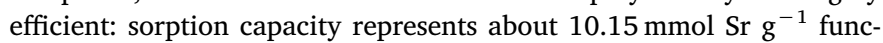
tionalized polymer (not taking into account silica contribution to sorbent weight).

\subsubsection{Sorption mechanism}

The combination of data collected from the characterization sections and the sorption performances ( $\mathrm{pH}$ effect and sorption isotherms) allows suggesting the main interactions involved in $\mathrm{Sr}$ (II) binding on $\mathrm{PAO}_{20} \mathrm{MAA}_{80} / \mathrm{SiO}_{2}$ (Scheme 5). The main reactive groups on the sorbent consist of carboxylic acid and amidoxime moieties. At the optimum $\mathrm{pH}$ (close to neutrality), the $\mathrm{pH}_{\mathrm{PZC}}$ value confirms the deprotonation of reactive groups. The slope analysis for $\mathrm{pH}$ effect (log plot of distribution coefficient $v s$. $\mathrm{pH}$ ) does not allow identifying ion-exchange mechanism and strontium is supposed to be bound through chelation. FTIR analysis shows the contribution of carboxylic and amidoxime (through $-\mathrm{NH},-\mathrm{NH}_{2}, \mathrm{C}=\mathrm{O}$ and $-\mathrm{OH}$ functions). The molar ratio between carboxyl and amidoxime groups in $\mathrm{PAO}_{20} \mathrm{MAA}_{80} / \mathrm{SiO}_{2}$ may explain the diversity of interaction modes, which is also confirmed by XPS analysis (identification of $-\mathrm{N}-\mathrm{Sr}$ and $-\mathrm{O}-\mathrm{Sr}$ bonds). Interactions may be of electrostatic and non-electrostatic nature due to deprotonation or electron delocalization of $\mathrm{O}$ - and $\mathrm{N}$-based functional groups (Scheme 5).

\subsubsection{Selectivity study}

The selectivity of the sorbent for Sr(II) against other alkali and alkali-earth metal ions is shown in Fig. AM13. The fraction of strontium on the sorbent at equilibrium varies between $41 \%$ and $59 \%$ while varying the $\mathrm{pH}$. The highest fractions are obtained at $\mathrm{pH}$ higher than 7. This is a first evidence that the sorbent has a marked preference for $\mathrm{Sr}$ (II). Indeed, the fraction in the solid is significantly enriched compared with the initial fraction in the solution (i.e., 20\%). The cumulative 


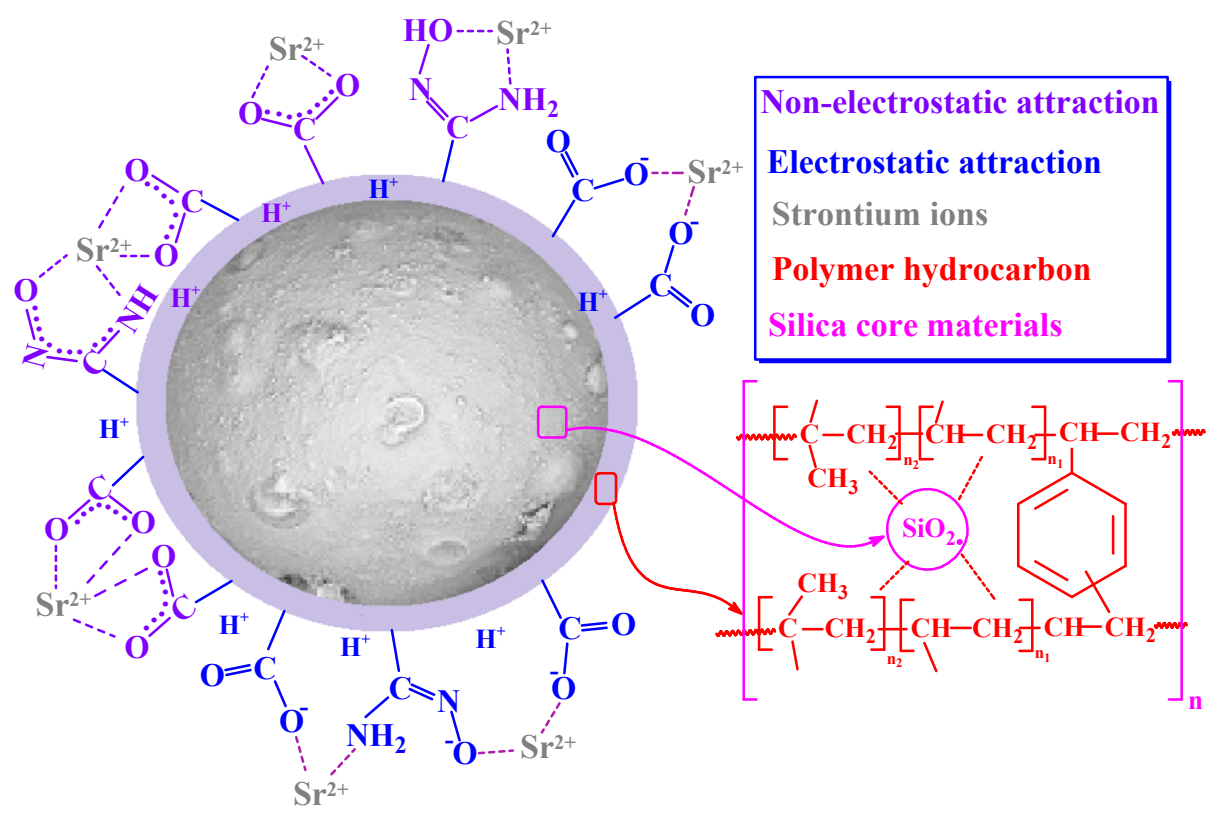

Scheme 5. Suggested mechanisms of Sr(II) sorption on bi-functionalized composite sorbent.

sorption capacity increases with up to $\mathrm{pH} 5.39$ ( $\left.1.39 \mathrm{mmol} \mathrm{metal} \mathrm{g}^{-1}\right)$

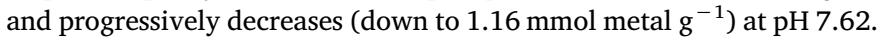

On the other hand, consistently with the results obtained with single-component solutions, $\mathrm{Sr}(\mathrm{II})$ sorption continuously increases with $\mathrm{pH}$ and reaches (under selected experimental conditions) a sorption

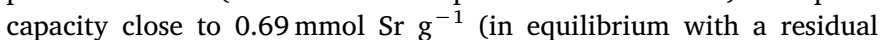

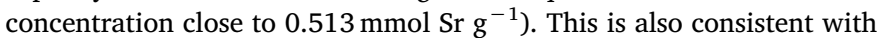
the sorption capacity reached on the sorption isotherm (single-component) for the same residual concentration (i.e., $\approx 0.7 \mathrm{mmol} \mathrm{Sr} \mathrm{g}^{-1}$ calculated from Freundlich and Sips equations, which provide the best fits of experimental isotherm in this concentration range). This means that the presence of co-ions in large excess does not impact the sorption capacity of Sr(II); although these co-ions can be bound to the sorbent (probably on other reactive groups). The cumulative sorption capacity

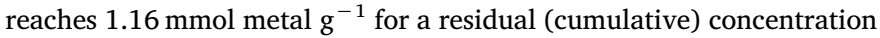
close to $5.16 \mathrm{mmol}$ metal $\mathrm{L}^{-1}$. This concentration corresponds to the saturation plateau of the $\mathrm{Sr}$ (II) single-component isotherm at $\mathrm{pH} 8$; the sorption capacity is found close to $1.36 \mathrm{mmol} \mathrm{Sr} \mathrm{g}^{-1}\left(1.38 \mathrm{mmol} \mathrm{Sr} \mathrm{g}^{-1}\right.$ for simulated value, using the Langmuir equation). The multi-component solutions decreases by $16 \%$ the total sorption capacity compared with the corresponding residual concentration in mono-component solution. The sorbent is remarkably stable in sorption performance: $\mathrm{Sr}$ (II) sorption is hardly affected by the presence of competitor or co-ions and the total sorption capacity is of the same order of magnitude (though slightly lower than for $\mathrm{Sr}(\mathrm{II})$-single solutions). It is noteworthy that at $\mathrm{pH} 5.39, \mathrm{Ca}(\mathrm{II})$ sorption is relatively higher than the sorption of $\mathrm{Ba}(\mathrm{II}), \mathrm{K}(\mathrm{I})$ and $\mathrm{Na}(\mathrm{I})$.

Table AM10 shows the semi-quantitative analysis of $\mathrm{PAO}_{20} \mathrm{MAA}_{80}$ / $\mathrm{SiO}_{2}$ sorbent (surface) after being mixed with multi-component solutions at different $\mathrm{pH}$ values. These results confirm the relative selectivity of the sorbent for $\mathrm{Sr}(\mathrm{II})$. The atomic fraction at the surface of the sorbent for co-ions (i.e., $\mathrm{Na}(\mathrm{I}), \mathrm{K}(\mathrm{I}), \mathrm{Ca}(\mathrm{II})$ and $\mathrm{Ba}(\mathrm{II})$ ) remains systematically below $0.08 \%$ while for $\operatorname{Sr}($ II) the content increases with $\mathrm{pH}$ from 3 (i.e., $0.15 \%$ ) up to $0.86-0.84 \%$ at $\mathrm{pH} 6-7$, and increases again at $\mathrm{pH} 10$ (up to $1.07 \%$ ). The cumulative atomic fraction for coions ions does not exceed $0.22 \%$ at $\mathrm{pH} 6$ to $\mathrm{pH}$ 8. In multi-component solutions, the sorbent shows a $\mathrm{pH}$-response consistent with the results obtained with mono-component solutions.

Fig. 5 shows the selectivity coefficient $\left(\mathrm{SC}_{\mathrm{Sr} / \text { metal }}=\mathrm{D}_{\mathrm{Sc}} / \mathrm{D}_{\text {metal }}\right)$ of $\mathrm{Sr}$ (II) against $\mathrm{Ba}(\mathrm{II}), \mathrm{Ca}(\mathrm{II}), \mathrm{K}(\mathrm{I})$ and $\mathrm{Na}(\mathrm{I})$, at selected $\mathrm{pH}$ values. Regardless of the $\mathrm{pH}$ the $\mathrm{SC}$ is higher than 3; this confirms the preference of the sorbent for $\mathrm{Sr}$ (II) over selected metal cations. However, the SC is strongly affected by the $\mathrm{pH}$. Indeed, above $\mathrm{pH} 5$ the SC tends to increase, especially between 7 and 7.6. Against $\mathrm{Ba}(\mathrm{II}), \mathrm{Ca}(\mathrm{II}), \mathrm{K}(\mathrm{I})$ and $\mathrm{Na}$ (I), the $\mathrm{SC}$ reaches a maximum at $\mathrm{pH} 7.62$ with values ranging between 10.7 against $\mathrm{Na}(\mathrm{I})$ up to 17.6 against $\mathrm{K}(\mathrm{I})$. $\mathrm{PAO}_{20} \mathrm{MAA}_{80} / \mathrm{SiO}_{2}$ preference for $\mathrm{Sr}(\mathrm{II})$ against other alkali-earth metal ions (such as $\mathrm{Ca}(\mathrm{II})$ or $\mathrm{Ba}(\mathrm{II})$ is confirmed by the $\mathrm{SC}$ ranging between 12 and 14.2 at $\mathrm{pH}_{0}=8$ $\left(\mathrm{pH}_{\mathrm{eq}}=7.62\right)$. At $\mathrm{pH} 6$, where the differences are more marked between the different systems $\left(\mathrm{SC}_{\mathrm{Sr} / \text { metal }}\right)$, the selectivity increases according: $\mathrm{Ca}(\mathrm{II})<\mathrm{Na}(\mathrm{I})<\mathrm{Ba}(\mathrm{II})<\mathrm{K}$ (I). This ranking was compared with the relative values of different physicochemical properties of these elements (summarized in Table AM11). Actually, a relatively good correlation can be found between the $\mathrm{SC}_{\mathrm{Sr} / \text { metal }}$ parameters and the relative Pauling electronegativity ratios $\left(\chi_{\text {metal }} / \chi_{\text {sr }}\right)$, as shown in Fig. AM14.

Fig. AM15 provides complementary information on the comparison of sorption properties for selected metals. The $\log _{10}$ plots of the distribution ratios is plotted against equilibrium $\mathrm{pH}$. The superimposition of the experimental points for Sr(II) sorption in multi-component

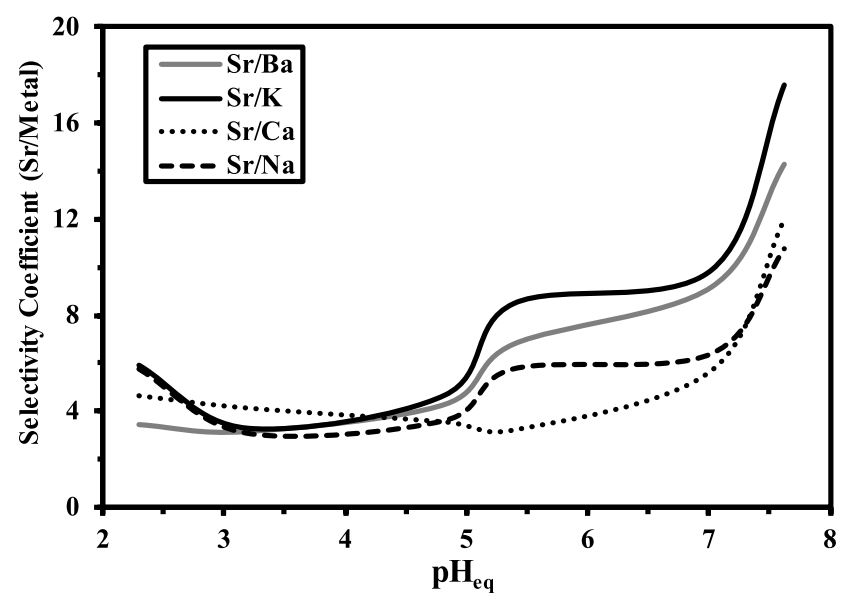

Fig. 5. Effect of $\mathrm{pH}$ on the selectivity coefficient for separation of $\mathrm{Sr}$ from monoand divalent cations (multi-component equimolar concentrations; $\mathrm{C}_{0}$ (individual): $1.3 \mathrm{mmol}$ metal $\mathrm{L}^{-1}$; SD: $0.125 \mathrm{~g} \mathrm{~L}^{-1}$; agitation time: $48 \mathrm{~h}$; agitation speed: $170 \mathrm{rpm}$; $\left.\mathrm{T}: 22 \pm 2{ }^{\circ} \mathrm{C}\right)$. 
solutions with the curve obtained from mono-comp onent solutions (filled symbols) confirms that the sorption of Sr(II) is hardly affected by the presence of these co-ions. In addition, the sorption levels $\left(\mathrm{D}_{\mathrm{Sc}}\right)$ are significantly higher than those observed for the other co-ions. In the case of $\mathrm{Sr}(\mathrm{II}$ ), the curve is linear between $\mathrm{pH} 2$ and 8 (and stabilizes above), while for the other metals a slope break is observed at the maximum between pH 5 and pH 6: this is consistent with the enhanced selectivity of the sorbent for $\mathrm{Sr}(\mathrm{II})$ at $\mathrm{pH}$ higher than 6 . The ranking in sorption for alkali and alkali-earth metal ions at the optimum $\mathrm{pH}$ follows the series: $\mathrm{Ca}(\mathrm{II})>\mathrm{Na}(\mathrm{I})>\mathrm{Ba}(\mathrm{II})>\mathrm{K}(\mathrm{I})$. This ranking cannot be directly correlated to the charge of metal ions. Table AM11 reports the main physicochemical characteristics of selected metal ions. Actually, the ranking does not follow the ionic radius of hydrated species (Shannon data) [57]: $\mathrm{Na}\left(\mathrm{H}_{2} \mathrm{O}\right)_{6}{ }^{+}(1.02 \AA)<\mathrm{Ca}\left(\mathrm{H}_{2} \mathrm{O}\right)_{8}{ }^{+}(1.12 \AA)<\mathrm{Ba}$ $\left(\mathrm{H}_{2} \mathrm{O}\right)_{8}{ }^{+}(1.42 \AA)<\mathrm{K}\left(\mathrm{H}_{2} \mathrm{O}\right)_{8}{ }^{+}(1.51 \AA)$. A better correlation is reported with Pauling electronegativity $\mathrm{Ca}(\mathrm{II})(1)>\mathrm{Na}(\mathrm{I}) \quad(0.93)>\mathrm{Ba}(\mathrm{II})$ (0.89) $>\mathrm{K}(\mathrm{I})$ (0.82). This confirms t he i nfluence of co -ion electronegativity on the selectivity of $\mathrm{Sr}(\mathrm{II})$ sorption using $\mathrm{PAO}_{20} \mathrm{MAA}_{80} / \mathrm{SiO}_{2}$.

\subsubsection{Metal desorption and sorbent recycling}

Metal desorption is a critical step in the design of a sorption process since the recovery of the metal and the recycling or the sorbent are imperative for the competitiveness of the treatment. Fig. AM16 shows the p erfect rep roducibility of desorp tion kinetics. Fig. 6 shows the desorp tion kinetics for Sr(II) elution from loaded $\mathrm{PAO}_{20} \mathrm{MAA}_{80} / \mathrm{SiO}_{2}$ using $0.5 \mathrm{M} \mathrm{HCl}$ solutions. The desorption profiles are very close for the different levels of $\operatorname{Sr}(\mathrm{II})$ loadings: the desorption is little slower with the

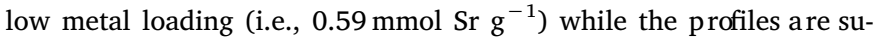

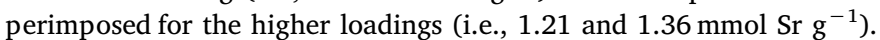
The sorption kinetic profiles were not superimposed (Fig. 2). Complete metal desorp tion occurs within $20-30 \mathrm{~min}$ of contact; this is shorter than the equilibrium time required for metal sorption (40-60 min). The PFORE better fits desorption kinetics than the PSORE (especially considering the comp lete desorp tion for PFORE while PSORE modeling does not achieve complete metal elution); this is another significant difference with the sorp tion s tep, where the differences be tween the models were less significant. The apparent rate coefficient (for PFORE) are little higher than the values obtained during sorption step (Tables 2 and 5).

Table 6 compares the performances of sorption and desorption for Sr(II) removal using $\mathrm{PAO}_{20} \mathrm{MAA}_{80} / \mathrm{SiO}_{2}$ for five successive cycles. The desorption of $\mathrm{Sr}$ (II) from metal-loaded resin is very efficient and stable for 5 cycles using $0.5 \mathrm{M} \mathrm{HCl}$ solution as the eluent: metal desorption is completely achieved for, at least, the first five cycles. The sorption efficiency p rogressively d ecreases ( from $58.3 \pm 0.5 \%$ to $54.5 \pm 0.1 \%$ ). This 6.5\%-loss in sorption efficiency (despite the complete desorption of the metal), is probably due to a partial degradation of the sorbent. This is an important parameter for higher number of recycling cycles. However, the combined sorption/desorption performances are globally very attractive for the selective recovery of $\mathrm{Sr}(\mathrm{II})$ from complex solutions.

\subsubsection{Dynamic sorption - fixed-bed column}

The resins were applied in fixed-bed column for dynamic sorption (Fig. 7 and Fig. AM17). The breakthrough curves are correctly fitted by the Thomas equation [55] (Table 7). The rep roducibility of breakthrough curves is clearly demonstrated by the superposition of experimental p rofiles. The comparison of 1 inear (LR) and non-linear (NLR) regression analysis shows that the non-linear regression analysis gives a better mathematical fit. Increasing the flow rate (and superficial velocity) improves the quality of the fit. The calculated sorption capacity is consistent with the experimental values (little overestimation, by less than $4 \%$ for LR); in the case of NLR, the sorption cap acity is more overestimated (despite the better global fit of experimental profiles). Surp risingly, the sorption capacity linearly decreases with superficial velocity (while using the same amount of sorbent and the same initial metal concentration); this means that the saturation of the sorbent is not achieved. The expected sorption capacity at equilibrium is deduced from the sorption isotherms (close to $0.74 \mathrm{mmol} \mathrm{Sr}^{-1}$ ). The sorption capacities obtained in dynamic system are systematically much lower than the expected value, from $0.247-0.270$ to $0.535-0.544 \mathrm{mmol} \mathrm{Sr}$ $\mathrm{g}^{-1}$, depending on the flow rate. This is another confirmation that the sorbent is not fully saturated. Ang et al. [96] observed close values for the saturation capacities in the case of the sorption of anesthetic gaseous agent on activated carbon when varying the flow rate. The rate coefficient $\mathrm{k}_{\mathrm{T}}\left(\mathrm{L} \mathrm{mmol}{ }^{-1} \mathrm{~h}^{-1}\right.$ ) linearly increases with the superficial velocity (between 0.32 and $2.390 \mathrm{~L} \mathrm{mmol}^{-1} \mathrm{~h}^{-1}$ for LR; between 0.246 and $2.09 \mathrm{mmol}^{-1} \mathrm{~h}^{-1}$ for NLR); consistently with the conclusions raised by Ang et al. [96]. In the case of base metals using melamine-functionalized SBA-15 mesoporous silica, Shabazi et al. [97] reported that a maximum sorption capacity was obtained at intermediary flow rate; the relevant sorption capacities were also lower than the corresponding sorption capacities obtained in batch mode. Araneda et al. [98] investigated the dynamic sorption of copper on extractant-immobilized microcapsules; they also observed a significant decrease of the sorption capacity calculated by the Thomas model with increasing the flow rate. The rate coefficient also increased with the flow rate.

\subsubsection{Sr(II) sorption from seawater}

The semi-quantitative EDX analysis of seawater treatment by sorption onto $\mathrm{PAO}_{20} \mathrm{MAA}_{80} / \mathrm{SiO}_{2}$ is reported in Table AM12 for different $\mathrm{pH}$ values. The $\mathrm{SiO}_{2}$ core is appearing through the two major peaks of EDX spectra for $\mathrm{Si}$ and O elements that represent between 69 and $77 \%$ of the sorbent (atomic fractions, AF). The polymer coating is associated to $\mathrm{C}$ content, which increases from 9 to $12 \%(\mathrm{AF})$ when the $\mathrm{pH}$ increases from 4 to 8-10: this $C$ increases may be explained by the formation of carbonate complexes or the accumulation of organic materials
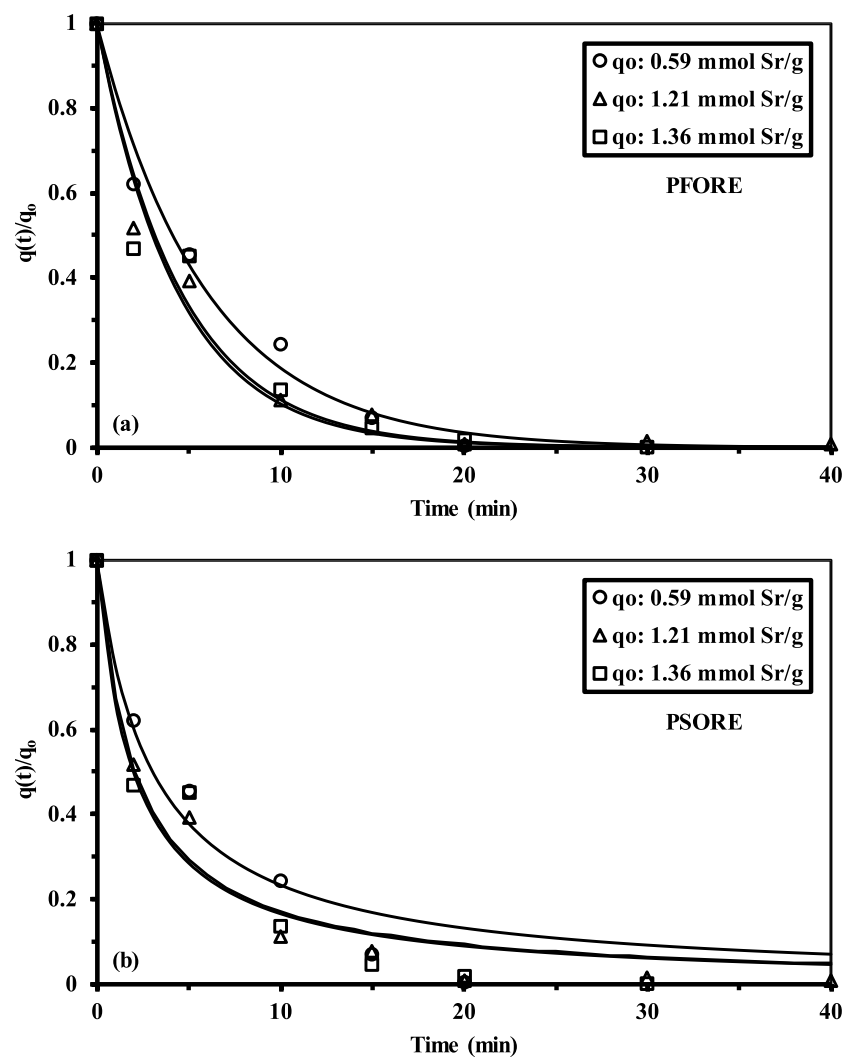

Fig. 6. $\mathrm{Sr}(\mathrm{II})$ desorption kinetics from metal-loaded $\mathrm{PAO}_{20} \mathrm{MAA}_{80} / \mathrm{SiO}_{2}-$ Modeling with the PFORE (a) and the PSORE (b) (sorbent collected from uptake kinetic experiments; desorption conditions: $0.5 \mathrm{M} \mathrm{HCl}$ as eluent; SD: $1 \mathrm{~g} \mathrm{~L}^{-1}$; agitation speed: $170 \mathrm{rpm}$; $\mathrm{T}: 22 \pm 2{ }^{\circ} \mathrm{C}$ ). 
Table 5

Parameters of kinetic models for Sr(II) desorp tion from metal-loaded $\mathrm{PAO}_{20} \mathrm{MAA}_{80} / \mathrm{SiO}_{2}$ using the PFORE and PSORE fits [54].

\begin{tabular}{|c|c|c|c|c|c|c|}
\hline \multirow{2}{*}{$\begin{array}{l}\text { Loaded conc. } \\
\left(\mathrm{mmol} \mathrm{Sr} \mathrm{g}^{-1}\right)\end{array}$} & \multirow{2}{*}{$\begin{array}{l}\text { Model } \\
\text { Parameter }\end{array}$} & \multicolumn{2}{|l|}{ PFORE } & \multicolumn{3}{|c|}{ PSORE } \\
\hline & & $\mathrm{k}_{\mathrm{D} 1}\left(\min ^{-1}\right)$ & $\mathrm{R}^{2}$ & $\beta_{2}$ & $\mathrm{k}_{\mathrm{D} 2}\left(\min ^{-1}\right)$ & $\mathrm{R}^{2}$ \\
\hline Run \#1 - 0.590 & & 0.171 & 0.985 & 0.989 & 0.319 & 0.970 \\
\hline Run \#2 - 0.591 & & 0.163 & 0.970 & 0.990 & 0.327 & 0.964 \\
\hline 1.21 & & 0.228 & 0.979 & 0.992 & 0.492 & 0.973 \\
\hline 1.36 & & 0.218 & 0.949 & 1.000 & 0.484 & 0.951 \\
\hline
\end{tabular}

PFORE: $\frac{q(t)}{q_{0}}=e^{-k_{D 1} t}$ with: $\mathrm{k}_{\mathrm{D} 1}$ the apparent rate coefficient for desorption $\left(\min ^{-1}\right)$ PSORE: $\frac{q(t)}{q_{0}}=\frac{1}{\beta_{2}+k_{D 2} t}$ with: $\mathrm{k}_{\mathrm{D} 2}$ the apparent rate coefficient for desorption ( $\mathrm{min}^{-1}$ ) and $\beta_{2}$ (dimensionless) the constant for PSORE (in desorption).

Table 6

$\mathrm{Sr}(\mathrm{II})$ sorption and desorption efficiencies for $\mathrm{PAO}_{20} \mathrm{MAA}_{80} / \mathrm{SiO}_{2}$ sorbent recycling.

\begin{tabular}{|c|c|c|c|c|}
\hline \multirow[t]{2}{*}{ Cycle \# } & \multicolumn{2}{|c|}{ Sorption efficiency (\%) } & \multicolumn{2}{|c|}{ Desorption efficiency (\%) } \\
\hline & Average & S.D. & Average & S.D. \\
\hline 1 & 58.3 & 0.5 & 100.1 & 0.4 \\
\hline 2 & 57.0 & 0.4 & 100.3 & 0.6 \\
\hline 3 & 56.4 & 0.2 & 100.3 & 0.5 \\
\hline 4 & 54.8 & 0.2 & 100.0 & 0.6 \\
\hline 5 & 54.5 & 0.0 & 100.2 & 0.3 \\
\hline
\end{tabular}

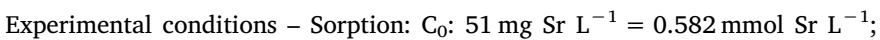
pH: 8.05; SD: $0.61 \mathrm{~g} \mathrm{~L}^{-1}$; time: $24 \mathrm{~h}$; $\mathrm{T}: 22 \pm 2^{\circ} \mathrm{C}$; agitation speed: $170 \mathrm{rpm} /$ Desorption: eluent: $1 \mathrm{M} \mathrm{HCl}$; SD: $1.5 \mathrm{~g} \mathrm{~L}^{-1}$; time: $2 \mathrm{~h} \mathrm{~T}$ : $22 \pm 2{ }^{\circ} \mathrm{C}$; agitation speed: $170 \mathrm{rpm}$.

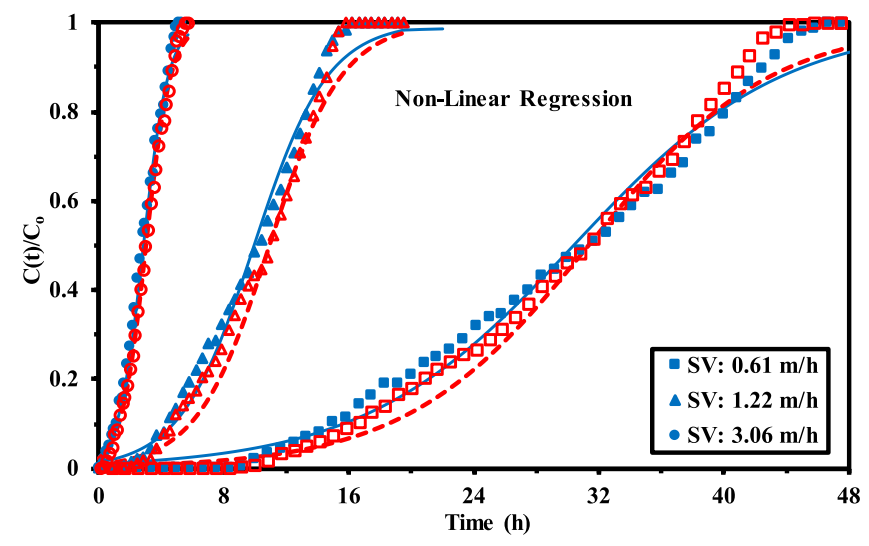

Fig. 7. Breakthrough curves for the sorption of $\mathrm{Sr}(\mathrm{II})$ using $\mathrm{PAO}_{20} \mathrm{MAA}_{80} / \mathrm{SiO}_{2}-$ effect of superficial velocity (sorbent weight $400 \mathrm{mg} ; \mathrm{pH}_{0}: 8$ ); modeling of experimental breakthrough curves with the Thomas equation; Run \#1 (closed symbols and solid lines) $\mathrm{C}_{0}$ : $53 \mathrm{mg} \mathrm{Sr} \mathrm{^{-1 }}=0.605 \mathrm{mmol} \mathrm{Sr} \mathrm{L}^{-1}$; Run \#2 (open symbols and dashed lines) $\mathrm{C}_{0}: 54 \mathrm{mg} \mathrm{Sr} \mathrm{L}^{-1}=0.615 \mathrm{mmol} \mathrm{Sr} \mathrm{L}^{-1}$; parameters determined by non-linear regression analysis).

contained in seawater that can bound to the sorbent active sites. Similarly, for S element: the content increases in neutral or alkaline solutions, probably associated to the binding of sulfate, hydrogen sulfate or metal sulfate. The amount of $\mathrm{N}$ element (in the range 4.64-6.34 \%, $\mathrm{AF}$ ) is due to amidoxime moiety. Strontium content increases from $0.04 \%$ at $\mathrm{pH} 4$ to $0.54-0.46 \%$ at $\mathrm{pH} 8-10$. This is consistent with the previous results obtained with synthetic solutions. Consistently with the trends observed for multi-component synthetic solutions, $\mathrm{Ca}(\mathrm{II})$ sorption hardly varies between 0.22 and $0.37 \%, \mathrm{~K}(\mathrm{I})$ between 0.01 and $0.15 \%, \mathrm{Mg}(\mathrm{II})$ between 0.16 and $0.36 \%$ (increasing with $\mathrm{pH}$ ). The case of $\mathrm{Na}(\mathrm{I})$ is little different: $\mathrm{Na}$ content continuously decreases with $\mathrm{pH}$ (from 3.22 to $0.04 \%$ ). Other elements are identified on EDX spectra:
Table 7

Modeling of breakthrough curves for the sorption of $\mathrm{Sr}(\mathrm{II})$ using $\mathrm{PAO}_{20} \mathrm{MAA}_{80}$ / $\mathrm{SiO}_{2}$ at different flow rates ( $\mathrm{Q}, \mathrm{mL} \mathrm{min}{ }^{-1}$; Superficial flow velocity, $\mathrm{SV}, \mathrm{m} \mathrm{h}^{-1}$ ) - Parameters of the Thomas model [55].

\begin{tabular}{|c|c|c|c|c|c|c|c|}
\hline $\mathrm{Q}$ & SV & Run & $\begin{array}{l}\text { qexp. (mmol } \\
\left.\mathrm{Sr}^{-1}\right)\end{array}$ & Regr. & $\begin{array}{l}\mathrm{q}_{\text {model }}(\mathrm{mmol} \\
\left.\mathrm{Sr}^{-1}\right)\end{array}$ & $\begin{array}{l}\mathrm{k}_{\mathrm{T}}(\mathrm{L} \\
\left.\mathrm{mmol}^{-1} \mathrm{~h}^{-1}\right)\end{array}$ & $\mathrm{R}^{2}$ \\
\hline \multirow[t]{4}{*}{0.2} & 0.61 & $\# 1$ & 0.535 & $\mathrm{~L}$ & 0.533 & 0.320 & 0.975 \\
\hline & & & & NL & 0.551 & 0.246 & 0.989 \\
\hline & & $\# 2$ & 0.544 & $\mathrm{~L}$ & 0.527 & 0.357 & 0.978 \\
\hline & & & & NL & 0.562 & 0.279 & 0.994 \\
\hline \multirow[t]{4}{*}{0.4} & 1.22 & $\# 1$ & 0.346 & $\mathrm{~L}$ & 0.357 & 0.829 & 0.984 \\
\hline & & & & NL & 0.359 & 0.702 & 0.993 \\
\hline & & \#2 & 0.372 & $\mathrm{~L}$ & 0.381 & 0.843 & 0.983 \\
\hline & & & & NL & 0.403 & 0.705 & 0.992 \\
\hline \multirow[t]{4}{*}{1.0} & 3.06 & $\# 1$ & 0.247 & $\mathrm{~L}$ & 0.258 & 2.328 & 0.993 \\
\hline & & & & NL & 0.256 & 2.090 & 0.996 \\
\hline & & \#2 & 0.270 & $\mathrm{~L}$ & 0.278 & 2.390 & 0.994 \\
\hline & & & & NL & 0.279 & 2.057 & 0.997 \\
\hline
\end{tabular}

$\mathrm{q}_{\mathrm{th} .}=0.707 \mathrm{mmol} \mathrm{Sr} \mathrm{g}^{-1} ; \mathrm{L}$ : linear regression, NL: non-linear regression analysis.

Thomas equation: $\ln \left(\frac{C_{0}}{C(t)}-1\right)=\frac{k_{T} q_{e q} m}{Q}-k_{T} C_{0} t$.

Where $\mathrm{k}_{\mathrm{T}}$ is the Thomas rate constant $\left(\mathrm{L} \mathrm{mg}^{-1} \mathrm{~h}^{-1}\right), \mathrm{q}_{\mathrm{eq}}$ the sorption capacity at equilibrium ( $\mathrm{mmol} \mathrm{Sr} \mathrm{g}^{-1}$ ), $\mathrm{m}$ the amount of sorbent $(\mathrm{g})$, $\mathrm{Q}$ the flow rate ( $\mathrm{L}$ $\left.\mathrm{h}^{-1}\right)$; $\mathrm{t}$ the time $(\mathrm{h}), \mathrm{C}_{0}$ and $\mathrm{C}(\mathrm{t})$ : the inlet and outlet concentrations, respectively.

such as $\mathrm{B}(\mathrm{III}), \mathrm{Mo}(\mathrm{VI})$ and $\mathrm{Ru}(\mathrm{III})$. A special attention has been paid to the sorption kinetics of this series of metals or elements at different $\mathrm{pH}$ values. Fig. AM1 8 compares the kinetic profiles for traces removal: for B (III) and Sr(II) the residual concentration progressively decreases up to $48 \mathrm{~h}$; the sorption of $\mathrm{Mo}(\mathrm{VI})$ is much faster (a pseudo-equilibrium, corresponding to $90 \%$ of total sorption, is reached within $6-10 \mathrm{~h}$ ). For the other (major) elements (not shown), at much higher concentration, the variation of the concentration in the solution is relatively weak (less than $3 \%$, and even less than $1 \%$ for $\mathrm{Na}(\mathrm{I})$ and $\mathrm{K}(\mathrm{I})$ ); the equilibrium is reached within $12-24 \mathrm{~h}$.

The sorption capacities are directly controlled by their metal concentration in seawater (Tables AM13 and AM14) and the pH of the solution: sorption capacities increase with $\mathrm{pH}$ (consistently with experiments on synthetic solutions), essentially between $\mathrm{pH} 4$ and $\mathrm{pH} 8$.

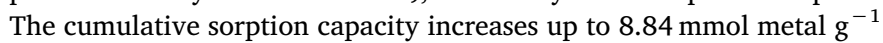
at $\mathrm{pH}$ 10. The $\mathrm{Sr}(\mathrm{II})$ sorption capacity increases from 0.071 to $0.103 \mathrm{mmol} \mathrm{Sr} \mathrm{g}^{-1}$ when the $\mathrm{pH}$ increases from 8 to 10 . Compared to the sorption isotherm obtained with synthetic pure solution, for a residual concentration close to $0.0104 \mathrm{mmol} \mathrm{Sr} \mathrm{L}^{-1}$ at $\mathrm{pH}$ 8, according the Sips equation (which fits the most closely the isotherm at low metal concentration), the expected sorption capacity should be close to $0.093 \mathrm{mmol} \mathrm{Sr} \mathrm{g}^{-1}$. This means that the loss in sorption capacity in such a complex solution does not exceed $25 \%$.

The most significant enrichments (compared with initial metal concentrations: $\mathrm{q}_{\mathrm{eq}} / \mathrm{C}_{0}, \mathrm{~L} \mathrm{~g}^{-1}$ ) are observed for trace elements such as Sr(II) (up to $3.32 \mathrm{~L} \mathrm{~g}^{-1}$ ), Mo(VI) (up to $3.16 \mathrm{~L} \mathrm{~g}^{-1}$ ) and B(III) (up to $1.37 \mathrm{~L} \mathrm{~g}^{-1}$ ) at $\mathrm{pH}_{0} 10$, while for the other metals the enrichment factor does not exceed $0.175 \mathrm{~L} \mathrm{~g}^{-1}$. The values of distribution ratio (D, $\mathrm{L} \mathrm{g}^{-1}$ ) are also summarized in Table AM14: highest D values are observed at $\mathrm{pH} 10$ for $\mathrm{Sr}(\mathrm{II})>\mathrm{Mo}(\mathrm{VI})$ and B(III). The selectivity coefficients for $\mathrm{Sr}$ over co-ions are reported in Fig. AM19. The SC increases with time and $\mathrm{pH}$. The systems are difficultly comparable due to the large excess in the concentration of the major elements; however, these data offer an easy comparison tool for highlighting the preference of the sorbent for $\mathrm{Sr}$ (II) over the co-ions. Highest SCs are observed according the sequence: $\mathrm{Na}$

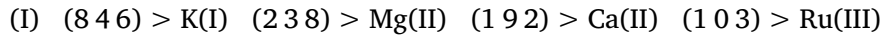
(62) $>\mathrm{B}$ (III) (5). On the opposite hand, the sorbent has a little preference for $\mathrm{Mo}(\mathrm{VI})$ against $\mathrm{Sr}(\mathrm{II})\left(\mathrm{SC}_{\mathrm{Sr} / \mathrm{Mo}}<1\right)$ at $\mathrm{pH} 4$ and 8; at $\mathrm{pH} 10$, the sorbent does not show selectivity between the two metal ions.

These results show that in such a complex solution as seawater, the 
sorbent maintains:

(a) good sorption properties for $\mathrm{Sr}(\mathrm{II})$,

(b) high affinity for other trace metal ions (B(III) and more specifically $\mathrm{Mo}(\mathrm{VI})$ ), and

(c) strong enrichment factor and high relative distribution ratios for these trace metal ions (despite huge excess of $\mathrm{Na}(\mathrm{I}), \mathrm{Mg}(\mathrm{II}), \mathrm{L}(\mathrm{I})$ and $\mathrm{Ca}(\mathrm{II}))$.

\section{Conclusion}

The combined grafting of both polyacrylic and amidoxime groups on silica microspheres (size: around $120 \mu \mathrm{m}$ ) allows enhancing the sorption properties of the composite for Sr(II), compared with monofunctional sorbents (bearing solely PMAA or PAO moieties). However, the comparison of sorption performances shows that maximum sorption efficiency for $\mathrm{Sr}(\mathrm{II})$ is reached for specific substitution grade (i.e., corresponding to $\mathrm{PAO}_{20} \mathrm{MAA}_{80} / \mathrm{SiO}_{2}$ composite sorbent). The sorbents are characterized by elemental analysis $\left(3.36-7.8 \mathrm{mmol} \mathrm{N} \mathrm{g}^{-1}\right.$ ), semiquantitative EDX analysis, textural properties (SSA: $62-69 \mathrm{~m}^{2} \mathrm{~g}^{-1}$ ), TGA (about $13.6 \%$ weight loss at $875{ }^{\circ} \mathrm{C}$, representing the hydrocarbon coating fraction), $\mathrm{pH}_{\mathrm{PZC}}\left(6.42-6.51\right.$ for $\mathrm{PAO}_{20} \mathrm{MAA}_{80} / \mathrm{SiO}_{2}$ composite sorbent). FTIR and XPS analyses confirm the appearance of functional groups on the polymer coating layer of composite materials, consistently with suggested synthesis procedures. In addition, the changes in spectra confirm the contribution of amine, hydroxyl/carboxyl groups in the binding of $\mathrm{Sr}(\mathrm{II})$ on the composite sorbent.

Optimum sorption occurs at $\mathrm{pH}$. The uptake is relatively fast: equilibrium is reached within $40-60 \mathrm{~min}$ of contact. The sorption is fitted by the pseudo-first order rate equation: apparent rate coefficient varies in the range $0.09-10.17 \mathrm{~min}^{-1}$. The maximum sorption capacity is closed to $1.38 \mathrm{mmol} \mathrm{Sr} \mathrm{g}^{-1}$ ( $10.15 \mathrm{mmol} \mathrm{Sr} \mathrm{g}^{-1}$ when reported in function of the effective amount of functionalized polymer in the composite); the isotherms are equally fitted by the Langmuir (capacity at saturation of the monolayer close to $1.57 \mathrm{mmol} \mathrm{Sr} \mathrm{g}^{-1}$ ) and the Sips equations. These sorption capacities are among the most promising compared with available literature data. The recycling of the sorbent is verified over 5 cycles of sorption and desorption: $1 \mathrm{M} \mathrm{HCl}$ solution offers complete, fast (equilibrium within $20 \mathrm{~min}$ ) and stable desorption of Sr(II) while the sorption efficiency slightly decreases (less than $7 \%$ at the fifth cycle). In equimolar multi-component solutions, the sorption is selective for Sr(II) over alkali and alkali earth metal ions. This is confirmed by the tests performed on $\mathrm{Sr}(\mathrm{II})$ sorption in seawater: high distribution ratio (in the range 1-10 $\mathrm{L} \mathrm{g}^{-1}$ ) are observed for $\mathrm{Sr}(\mathrm{II})$ and $\mathrm{B}$ (III) or Mo(VI), despite the huge excess of alkali and alkali-earth metal ions. In dynamic systems (i.e., fixed-bed column), the breakthrough curves for $\mathrm{Sr}$ (II) sorption are finely fitted by the Thomas model; although the sorption capacity is significantly under evaluated compared with static systems.

\section{Declaration of Competing Interest}

The authors declare that they have no known competing financial interests or personal relationships that could have appeared to influence the work reported in this paper.

\section{Acknowledgements}

M. R. acknowledges the China Scholarship Council (CSC, Grant N 2018DFH009893) for MSc fellowship. Y. W. thanks the support of NSFC Projects (No. 11675102, No. 11975082, U1967218), Science and Technology Major project of Guangxi Province (AA17204100, AA18118030). E.G. and M.F.H acknowledge Institut Francais d'Egypte for supporting the collaboration between IMT-Mines Ales and Nuclear Materials Authority, and IMHOTEP project "MetalValor" (funded by
Ministère des Affaires Etrangères and Ministère de l'Enseignement Supérieur et de la Recherche; and by Science and Technology Development Fund from Egyptian Academy of Science and Technology).

\section{Appendix A. Supplementary data}

Supplementary data to this article can be found online at https:// doi.org/10.1016/j.cej.2020.125220.

\section{References}

[1] K. Hirose, P.P. Povinec, Cs-137 and Sr-90 in surface waters of the Sea of Japan: Variations and the Fukushima Dai-ichi Nuclear Power Plant accident impact, Mar. Pollut. Bull. 146 (2019) 645-652.

[2] R. Querfeld, A.-E. Pasi, K. Shozugawa, C. Vockenhuber, H.-A. Synal, P. Steier, G. Steinhauser, Radionuclides in surface waters around the damaged Fukushima Daiichi NPP one month after the accident: evidence of significant tritium release into the environment, Sci. Total Environ. 689 (2019) 451-456.

[3] M. Konno, Y. Takagai, Determination and comparison of the strontium-90 concentrations in topsoil of fukushima prefecture before and after the Fukushima Daiichi nuclear accident, ACS Omega 3 (2018) 18028-18038.

[4] S.H. Kim, H. Lee, S.H. Lee, I. Kim, Distribution and accumulation of artificial radionuclides in marine products around Korean Peninsula, Mar. Pollut. Bull. 146 (2019) 521-531.

[5] T. Shubair, O. Eljamal, A. Tahara, Y. Sugihara, N. Matsunaga, Preparation of new magnetic zeolite nanocomposites for removal of strontium from polluted waters, J. Mol. Liq. 288 (2019).

[6] L.Y. Wu, G.H. Zhang, Q.Z. Wang, L. Hou, P. Gu, Removal of strontium from liquid waste using a hydraulic pellet co-precipitation microfiltration (HPC-MF) process, Desalination 349 (2014) 31-38.

[7] J.G. Cao, P. Gu, J. Zhao, D. Zhang, Y. Deng, Removal of strontium from an aqueous solution using co-precipitation followed by microfiltration (CPMF), J. Radioanal. Nucl. Chem. 285 (2010) 539-546.

[8] J.N. Sharma, P.N. Khan, P.S. Dhami, P. Jagasia, V. Tessy, C.P. Kaushik, Separation of strontium-90 from a highly saline high level liquid waste solution using 4,4' $\left(5^{\prime}\right)$ di-tert-butyldicyclohexano-18-crown-6 + isodecyl alcohol/n-dodecane solvent, Sep. Purif. Technol. 229 (2019).

[9] Y. Xu, Y. Gao, Y. Zhou, C. Fan, H. Hou, M. Zhang, Extraction behavior of strontium from nitric acid medium with $\mathrm{N}, \mathrm{N}^{\prime}$-dimethyl-N, $\mathrm{N}^{\prime}$-dioctyldiglycolamide, Solvent Extr. Ion Exch. 35 (2017) 507-518.

[10] R. Yavari, Y.D. Huang, A. Mostofizadeh, Sorption of strontium ions from aqueous solutions by oxidized multiwall carbon nanotubes, J. Radioanal. Nucl. Chem. 285 (2010) 703-710.

[11] C.K. Aslani, F. Belloni, B. Cetinkaya, V.V. Rondinella, Sorption studies of strontium on carbon nanotubes using the Box-Behnken design, Radiochim. Acta 102 (2014) 931-940.

[12] S. Hayakawa, S. Matsubara, Y. Sumi, S. Yamamoto, N. Kawamura, T. Nonami, Caesium and strontium adsorption ability of activated bamboo charcoal, Int. J. Nanotechnol. 15 (2018) 683-688.

[13] S. Kobayashi, K. Noda, H. Shibata, S. Matsubara, N. Kawamura, T. Nonami, Rice hull charcoal for adsorption of cesium and strontium in aqueous solution, Mater. Trans. 60 (2019) 458-463.

[14] L. Qiu, J.D. Feng, Y.D. Dai, S.Q. Chang, Biosorption of strontium ions from simulated high-level liquid waste by living Saccharomyces cerevisiae, Environ. Sci. Pollut. Res. 25 (2018) 17194-17206.

[15] D. Song, S.-J. Park, H.W. Kang, S.B. Park, J.-I. Han, Recovery of lithium(I) strontium(II), and lanthanum(III) using Ca-alginate beads, J. Chem. Eng. Data 58 (2013) 2455-2464.

[16] J. Maresova, M. Pipiska, M. Rozloznik, M. Hornik, L. Remenarova, J. Augustin, Cobalt and strontium sorption by moss biosorbent: Modeling of single and binary metal systems, Desalination 266 (2011) 134-141.

[17] K.V. Mahindrakar, V.K. Rathod, Utilization of banana peels for removal of strontium (II) from water, Environ. Technol. Innovation 11 (2018) 371-383.

[18] Y.M. Hu, X. Guo, C. Chen, J.L. Wang, Algal sorbent derived from Sargassum horner for adsorption of cesium and strontium ions: equilibrium, kinetics, and mass transfer, Appl. Microbiol. Biotechnol. 103 (2019) 2833-2843.

[19] M. Galambos, J. Kufcakova, P. Rajec, Sorption of strontium on Slovak bentonites, J. Radioanal. Nucl. Chem. 281 (2009) 347-357.

[20] W. Janusz, E. Skwarek, Study of sorption processes of strontium on the synthetic hydroxyapatite, Adsorption - J. Int. Ads. Soc. 22 (2016) 697-706.

[21] D. Alby, C. Charnay, M. Heran, B. Prelot, J. Zajac, Recent developments in nanostructured inorganic materials for sorption of cesium and strontium: Synthesis and shaping, sorption capacity, mechanisms, and selectivity - a review, J. Hazard. Mater. 344 (2018) 511-530.

[22] X. Xia, J. Shen, F. Cao, C.J. Wang, M. Tang, Q.Y. Zhang, S.S. Wei, A facile synthesis of hydroxyapatite for effective removal strontium ion, J. Hazard. Mater. 368 (2019) 326-335.

[23] R. Zuo, L. Meng, X. Guan, J.S. Wang, J. Yang, Y.H. Lin, Removal of strontium from aqueous solutions by acrylamide-modified attapulgite, J. Radioanal. Nucl. Chem. 319 (2019) 1207-1217.

[24] R. Zuo, S. Jin, J. Yang, J. Wang, X. Guan, L. Meng, Y. Teng, M. Chen, Removal of 
strontium from aqueous solutions by sodium dodecyl sulfate-modified palygorskite, J. Radioanal. Nucl. Chem. 321 (2019) 151-159.

[25] H.S. Hassan, A.M. El-Kamash, H.A.-S. Ibrahim, Evaluation of hydroxyapatite/poly (acrylamide-acrylic acid) for sorptive removal of strontium ions from aqueous solution, Environ. Sci. Pollut. Res. 26 (2019) 25641-25655.

[26] H.J. Hong, B.G. Kim, J. Ryu, I.S. Park, K.S. Chung, S.M. Lee, J.B. Lee, H.S. Jeong, H. Kim, T. Ryu, Preparation of highly stable zeolite-alginate foam composite for strontium(Sr-90) removal from seawater and evaluation of Sr adsorption performance, J. Environ. Manage. 205 (2018) 192-200.

[27] S.Y. Wang, S.Y. Ning, W. Zhang, S.C. Zhang, J. Zhou, X.P. Wang, Y.Z. Wei, Synthesis of carboxyl group functionalized silica composite resin for strontium removal, Mater. Des. 185 (2020) 9.

[28] R.O.A. Rahman, O.A.A. Moamen, N. Abdelmonem, I.M. Ismail, Optimizing the removal of strontium and cesium ions from binary solutions on magnetic nanozeolite using response surface methodology (RSM) and artificial neural network (ANN), Environ. Res. 173 (2019) 397-410.

[29] T. Kawamura, T. Ito, S.Y. Kim, Adsorption and separation behavior of strontium and yttrium using a silica-based CMPO adsorbent, J. Radioanal. Nucl. Chem. 320 (2019) 9-14.

[30] T.T. Li, F. He, Y.D. Dai, Prussian blue analog caged in chitosan surface-decorated carbon nanotubes for removal cesium and strontium, J. Radioanal. Nucl. Chem. 310 (2016) 1139-1145.

[31] A.V. Voronina, V.S. Semenishchev, Mechanism of strontium sorption by the mixed nickel-potassium ferrocyanide based on hydrated titanium dioxide, J. Radioanal. Nucl. Chem. 307 (2016) 577-590.

[32] O. Eljamal, T. Shubair, A. Tahara, Y. Sugihara, N. Matsunaga, Iron based nanoparticles-zeolite composites for the removal of cesium from aqueous solutions, J. Mol. Liq. 277 (2019) 613-623.

[33] T. Shubair, O. Eljamal, A.M.E. Khalil, A. Tahara, N. Matsunaga, Novel application of nanoscale zero valent iron and bimetallic nano-Fe/Cu particles for the treatment of cesium contaminated water, J. Environ. Chem. Eng. 6 (2018) 4253-4264.

[34] K. Mulani, V. Patil, N. Chavan, K. Donde, Adsorptive removal of strontium(II) using macroporous poly(AGE-co-EGDMA) beads modified with resorcin 4 arene, Bull. Mater. Sci. 42 (2019).

[35] N.N. Basargin, E.V. Demina, V.Y. Anikin, I.B. Kometiani, Strontium(II) sorption by complexing o-hydroxy-azo-o'-hydroxy functionalized polystyrene polymer sorbents, Russ. J. Inorg. Chem. 56 (2011) 2019-2023.

[36] V.Y. Anikin, N.N. Basargin, O.V. Tarasova, Y.G. Rozovskii, Strontium(II) sorption by complexing polymeric sorbents with various structures, Russ. J. Inorg. Chem. 54 (2009) 1507-1511.

[37] P. Asgari, S.H. Mousavi, H. Aghayan, H. Ghasemi, T. Yousefi, Nd-BTC metal-organic framework (MOF); synthesis, characterization and investigation on its adsorption behavior toward cesium and strontium ions, Microchem. J. 150 (2019) 104188, https://doi.org/10.1016/j.microc.2019.104188.

[38] H.J. Hong, J. Ryu, I.S. Park, T. Ryu, K.S. Chung, B.G. Kim, Investigation of the strontium (Sr(II)) adsorption of an alginate microsphere as a low-cost adsorbent for removal and recovery from seawater, J. Environ. Manage. 165 (2016) 263-270.

[39] M. Piechowicz, C.W. Abney, X. Zhou, N.C. Thacker, Z. Li, W. Lin, Design, synthesis, and characterization of a bifunctional chelator with ultrahigh capacity for uranium uptake from seawater simulant, Ind. Eng. Chem. Res. 55 (2016) 4170-4178.

[40] A.F. Shaaban, T.Y. Mohamed, D.A. Fadel, N.M. Bayomi, Removal of Ba(II) and Sr (II) ions using modified chitosan beads with pendent amidoxime moieties by batch and fixed bed column methods, Desalin. Water Treat. 82 (2017) 131-145.

[41] Y. Wei, K.A.M. Salih, S. Lu, M.F. Hamza, T. Fujita, T. Vincent, E. Guibal, Amidoxime functionalization of algal/polyethyleneimine beads for the sorption of Sr(II) from aqueous solutions, Molecules 24 (2019) 3893.

[42] A.M.A. Nada, N.A. El-Wakil, M.L. Hassan, A.M. Adel, Differential adsorption of heavy metal ions by cotton stalk cation-exchangers containing multiple functional groups, J. Appl. Polym. Sci. 101 (2006) 4124-4132.

[43] S.A. Younis, M.M. Ghobashy, G. Bassioni, A.K. Gupta, Tailored functionalized polymer nanoparticles using gamma radiation for selected adsorption of barium and strontium in oilfield wastewater, Arabian J. Chem. (2018).

[44] Y. Dai, R. Lv, D. Huang, Q. Tao, Sorption of uranium on a bifunctional polymer of diethylenetriaminepentaacetic acid cross-linked beta-cyclodextrin in the presence of humic acid: Kinetics, isotherms, and thermodynamics, Water Air Soil Pollut. 229 (2018).

[45] K.V. Syamala, K.A. Venkatesan, M.P. Antony, P.R.V. Rao, Kinetics of Eu(III) extraction in macroporous bifunctional phosphinic acid resin, Sep. Sci. Technol. 51 (2016) 2001-2007.

[46] S.D. Alexandratos, X.P. Zhu, M. Florent, R. Sellin, Polymer-supported bifunctional amidoximes for the sorption of uranium from seawater, Ind. Eng. Chem. Res. 55 (2016) 4208-4216.

[47] Y. Wei, J. Qian, L. Huang, D. Hua, Bifunctional polymeric microspheres for efficient uranium sorption from aqueous solution: synergistic interaction of positive charge and amidoxime group, RSC Adv. 5 (2015) 64286-64292.

[48] R.J. Qu, Y. Zhang, W.W. Qu, C.M. Sun, J. Chen, Y. Ping, H. Chen, Y.Z. Niu, Mercury adsorption by sulfur- and amidoxime-containing bifunctional silica gel based hybrid materials, Chem. Eng. J. 219 (2013) 51-61.

[49] X. Wang, L. Yuan, Y. Wang, Z. Li, J. Lan, Y. Liu, Y. Feng, Y. Zhao, Z. Chai, W. Shi, Mesoporous silica SBA-15 functionalized with phosphonate and amino groups for uranium uptake, Science China Chem. 55 (2012) 1705-1711.

[50] L. Tofan, C. Paduraru, I. Cretescu, A. Ceica, V. Neagu, Chelating sorbent containing two types of functional groups - hydroxamic acid and amidoxime for lead (II) ions effluent management, Environ. Eng. Manage. J. 9 (2010) 113-118.
[51] S.E. Kudaibergenov, Physicochemical, complexation and catalytic properties of polyampholyte cryogels, Gels (Basel, Switzerland) 5 (2019).

[52] M.V. Lopez-Ramon, F. Stoeckli, C. Moreno-Castilla, F. Carrasco-Marin, On the characterization of acidic and basic surface sites on carbons by various techniques, Carbon 37 (1999) 1215-1221.

[53] O. Falyouna, O. Eljamal, I. Maamoun, A. Tahara, Y. Sugihara, Magnetic zeolite synthesis for efficient removal of cesium in a lab-scale continuous treatment system, J. Colloid Interface Sci. 571 (2020) 66-79.

[54] N.K. Lazaridis, T.A. Pandi, K.A. Matis, Chromium(VI) removal from aqueous solutions by $\mathrm{Mg}-\mathrm{Al}-\mathrm{CO}_{3}$ hydrotalcite: Sorption-desorption kinetic and equilibrium studies, Ind. Eng. Chem. Res. 43 (2004) 2209-2215.

[55] D. Tiwari, S.M. Lee, Novel hybrid materials in the remediation of ground waters contaminated with As(III) and As(V), Chem. Eng. J. 204 (2012) 23-31.

[56] Y. Li, F.X. Song, L. Cheng, J. Qian, Q.L. Chen, Functionalized large-pore mesoporous silica microparticles for gefitinib and doxorubicin codelivery, Materials 12 (2019).

[57] I. Persson, Hydrated metal ions in aqueous solution: how regular are their structures? Pure Appl. Chem. 82 (2010) 1901-1917.

[58] T. Yu, J. Lin, J. Xu, T. Chen, S. Lin, X. Tian, Novel polyacrylonitrile/Na-MMT/ silica nanocomposite: co-incorporation of two different form nano materials into polymer matrix, Compos. Sci. Technol. 67 (2007) 3219-3225.

[59] L.W. Ji, C. Saquing, S.A. Khan, X.W. Zhang, Preparation and characterization of silica nanoparticulate-polyacrylonitrile composite and porous nanofibers, Nanotechnology 19 (2008) 9.

[60] I.A. Khan, T. Yasin, H. Hussain, Development of amidoxime functionalized silica by radiation-induced grafting, J. Appl. Polym. Sci. 134 (2017).

[61] D.N. Clausen, I.M.R. Pires, C.R.T. Tarley, Improved selective cholesterol adsorption by molecularly imprinted poly(methacrylic acid)/silica (PMAA-SiO2) hybrid material synthesized with different molar ratios, Mater. Sci. Eng., C 44 (2014) 99-108.

[62] M.S. Iqbal, Y. Jamil, T. Kausar, M. Akhtar, Thermal degradation study of glycidyl methacrylate acrylonitrile copolymers, J. Therm. Anal. Calorim. 96 (2009) 225-233.

[63] J. Zhang, Z. Lu, M. Wu, Q. Wu, J. Yang, Facile fabrication of poly(acrylic acid) hollow nanogels via in situ Pickering miniemulsion polymerization, Polym. Chem. 6 (2015) 6125-6128.

[64] Z. Zhao, X. Xie, Z. Wang, Y. Tao, X. Niu, X. Huang, L. Liu, Z. Li, Immobilization of Lactobacillus rhamnosus in mesoporous silica-based material: an efficiency continuous cell-recycle fermentation system for lactic acid production, J. Biosci. Bioeng. 121 (2016) 645-651.

[65] I. Ramalla, R.K. Gupta, K. Bansal, Effect on superhydrophobic surfaces on electrical porcelain insulator, improved technique at polluted areas for longer life and reliability, Int. J. Eng. Technol. 4 (2015) 509-519.

[66] S. Lu, L. Chen, M.F. Hamza, C. He, X. Wang, Y. Wei, E. Guibal, Amidoxime functionalization of a poly(acrylonitrile)/silica composite for the sorption of Ga (III) - application to the treatment of Bayer liquor, Chem. Eng. J. 368 (2019) 459-473.

[67] N. Liu, R.A. Assink, B. Smarsly, C.J. Brinker, Synthesis and characterization of highly ordered functional mesoporous silica thin films with positively chargeable$\mathrm{NH}_{2}$ groups, Chem. Commun. 9 (2003) 1146-1147.

[68] X. Zhang, R.F. Guan, D.Q. Wu, K.Y. Chan, Enzyme immobilization on aminofunctionalized mesostructured cellular foam surfaces, characterization and catalytic properties, J. Mol. Catal. B: Enz. 33 (2005) 43-50.

[69] A.M. Atta, A.A.H. Abdel-Rahman, M.F. Hamza, I.E. El Aassy, F.Y. Ahmed, Effect of crosslinker chemical structure and monomer compositions on adsorption of uranium (VI) ions based on reactive crosslinked acrylamidoxime acrylic acid resins, J. Dispersion Sci. Technol. 33 (2012) 490-496.

[70] J. Coates, Interpretation of infrared spectra, a practical approach, Encyclopedia of Analytical Chemistry, John Wiley \& Sons, Ltd., 2006, pp. 1-23.

[71] M.F. Hamza, Y. Wei, E. Guibal, Quaternization of algal/PEI beads (a new sorbent): characterization and application to scandium recovery from aqueous solutions, Chem. Eng. J. 383 (2020) 123210.

[72] Y. Wei, S. Wei, C. Liu, T. Chen, Y. Tang, J. Ma, K. Yin, S. Luo, Efficient removal of arsenic from groundwater using iron oxide nanoneedle array-decorated biochar fibers with high Fe utilization and fast adsorption kinetics, Water Res. 167 (2019).

[73] N.B. Colthup, L.H. Daly, S.E. Wiberley, Introduction to Infrared and Raman Spectroscopy, third. ed., Academic Press Inc, San Diego, CA (USA), 1990, p. 560.

[74] M.F. Hamza, A. Gamal, G. Hussein, M.S. Nagar, A.A.H. Abdel-Rahman, Y. Wei, E. Guibal, Uranium(VI) and zirconium(IV) sorption on magnetic chitosan derivatives - effect of different functional groups on separation properties, J. Chem. Technol. Biotechnol. 94 (2019) 3866-3882.

[75] A.A.H. Abdel-Rahman, I.E.E. El-Aassy, Y.A. Fadia, M.F. Hamza, Studies on the uptake of rare earth elements on polyacrylamidoxime resins from natural concentrate leachate solutions, J. Dispersion Sci. Technol. 31 (2010) 1128-1135.

[76] F.Q. Ma, B.R. Dong, Y.Y. Gui, M. Cao, L. Han, C.S. Jiao, H.T. Lv, J.J. Hou, Y. Xue, Adsorption of low-concentration uranyl ion by amidoxime polyacrylonitrile fibers, Ind. Eng. Chem. Res. 57 (2018) 17384-17393.

[77] R. Janus, M. Wadrzyk, P. Natkanski, P. Cool, P. Kustrowski, Dynamic adsorptiondesorption of methyl ethyl ketone on MCM-41 and SBA-15 decorated with thermally activated polymers, J. Ind. Eng. Chem. 71 (2019) 465-480.

[78] F. Wang, X.L. Wang, Y.J. Jiang, Z.W. Niu, W.S. Wu, H.X. Zhang, Study of adsorption performance and adsorption mechanism for U(VI) ion on modified polyacrylonitrile fibers, J. Radioanal. Nucl. Chem. 323 (2020) 366-377.

[79] D. Semitekolos, P. Kainourgios, C. Jones, A. Rana, E.P. Koumoulos, C.A. Charitidis, Advanced carbon fibre composites via poly methacrylic acid surface treatment; surface analysis and mechanical properties investigation, Compos. B 155 (2018) 
$237-243$.

[80] C. Cannilla, G. Bonura, F. Frusteri, D. Spadaro, S. Trocino, G. Neri, Development of an ammonia sensor based on silver nanoparticles in a poly-methacrylic acid matrix, J. Mater. Chem. C 2 (2014) 5778-5786.

[81] F. Li, X. Li, P. Cui, Y. Sun, Plasma-grafted amidoxime/metal-organic framework composites for the selective sequestration of U(VI), Environ. Sci. Nano 5 (2018) 2000-2008.

[82] H. Chen, D.D. Shao, J.X. Li, X.K. Wang, The uptake of radionuclides from aqueous solution by poly(amidoxime) modified reduced graphene oxide, Chem. Eng. J. 254 (2014) 623-634.

[83] R. Cheng, M. Kang, S.T. Zhuang, L. Shi, X. Zheng, J.L. Wang, Adsorption of Sr(II) from water by mercerized bacterial cellulose membrane modified with EDTA, J. Hazard. Mater. 364 (2019) 645-653.

[84] P. Lignier, J. Estager, N. Kardos, L. Gravouil, J. Gazza, E. Naffrechoux, M. Draye, Swift and efficient sono-hydrolysis of nitriles to carboxylic acids under basic condition: Role of the oxide anion radical in the hydrolysis mechanism, Ultrason. Sonochem. 18 (2011) 28-31.

[85] D. Gregurec, N. Politakos, L. Yate, S.E. Moya, Strontium confinement in polyacrylic acid brushes: a soft nanoarchitectonics approach for the design of titania coatings with enhanced osseointegration, Mol. Syst. Des. Eng. 4 (2019) 421-430.

[86] R. Williams, pKa data (compiled by R. Williams), http://www.chem.wisc.edu/ areas/reich/pkatable/pKa_compilation-1-Williams.pdf, Accessed: 4/6/2017.

[87] E.P. Serjeant, B. Dempsey, Ionisation constants of organic acids in aqueous solution. IUPAC Chemical Data Series, $\mathrm{N}^{\circ} 23$, Pergamon Press, Oxford; New York, 1979pp.

[88] N. Schüwer, H.-A. Klok, Tuning the $\mathrm{pH}$ sensitivity of poly(methacrylic acid) brushes, Langmuir 27 (2011) 4789-4796.

[89] A.M. El-Naggar, A.S. Emara, S.G.A. Alla, Effect of gamma irradiation on the metal sorption and separation of some divalent metals by some new polymeric bifunctional resins, J. Appl. Polym. Sci. 65 (1997) 1091-1101.

[90] Y. Marcus, Ion Properties, Marcel Dekker Inc, New York, NY, 1997, p. 259.

[91] M.V. Maslova, V.I. Ivanenko, L.G. Gerasimova, Effect of temperature on the kinetics of the sorption of strontium cations by a sorbent based on titanium phosphate, Russ. J. Phys. Chem. A 93 (2019) 1245-1251.

[92] S.M. Yakout, E. Elsherif, Investigation of strontium (II) sorption kinetic and thermodynamic onto straw-derived biochar, Part. Sci. Technol. 33 (2015) $579-586$.

[93] A.M.S. Oancea, A.R. Popescu, M. Radulescu, V. Weber, E. Pincovschi, M. Cox, Kinetics of cesium and strontium ions removal from wastewater on gel and macroporous resins, Solvent Extr. Ion Exch. 26 (2008) 217-239.

[94] G.E. Boyd, B.A. Soldano, Self-diffusion of cations in and through sulfonated polystyrene cation-exchange polymers, JACS 75 (1953) 6091-6099.

[95] R.K. Bajpai, A.K. Gupta, M.G. Rao, Single particle studies of binary and ternary cation exchange kinetics, AlChE J. 20 (1974) 989-995.

[96] T.N. Ang, B.R. Young, M. Taylor, R. Burrell, M.K. Aroua, S. Baroutian, Breakthrough analysis of continuous fixed-bed adsorption of sevoflurane using activated carbons, Chemosphere 239 (2020) 124839.

[97] A. Shahbazi, H. Younesi, A. Badiei, Functionalized SBA-15 mesoporous silica by melamine-based dendrimer amines for adsorptive characteristics of $\mathrm{Pb}(\mathrm{II}), \mathrm{Cu}(\mathrm{II})$ and Cd(II) heavy metal ions in batch and fixed bed column, Chem. Eng. J. 168 (2011) 505-518.

[98] C. Araneda, C. Basualto, J. Sapag, C. Tapia, D. Cotorás, F. Valenzuela, Uptake of copper (II) ions from acidic aqueous solutions using a continuous column packed with microcapsules containing a $\beta$-hydroxyoximic compound, Chem. Eng. Res. Des. 89 (2011) 2761-2769.

[99] D.E. Chirkst, T.E. Litvinova, O.V. Cheremisina, M.V. Ivanov, N.A. Mironenkova, Isotherm of strontium sorption on clay, Russ. J. Appl. Chem. 76 (2003) 727-730.

[100] A. Ahmadpour, M. Zabihi, M. Tahmasbi, T.R. Bastami, Effect of adsorbents and chemical treatments on the removal of strontium from aqueous solutions, $\mathrm{J}$. Hazard. Mater. 182 (2010) 552-556.

[101] Y.W. Chen, J.L. Wang, Removal of radionuclide $\mathrm{Sr}^{2+}$ ions from aqueous solution using synthesized magnetic chitosan beads, Nucl. Eng. Des. 242 (2012) 445-451.

[102] P. Cakir, S. Inan, Y. Altas, Investigation of strontium and uranium sorption onto zirconium-antimony oxide/polyacrylonitrile ( $\mathrm{Zr}$-Sb oxide/PAN) composite using experimental design, J. Hazard. Mater. 271 (2014) 108-119.

[103] B. Maranescu, A. Popa, L. Lupa, V. Maranescu, A. Visa, Use of chitosan complex with aminophosphonic groups and cobalt for the removal of $\mathrm{Sr}^{2+}$ ions, Sep. Sci. Technol. 53 (2018) 1058-1064.

[104] E. Karabayir, A. Ozdemir, B.F. Senkal, O.S. Taskin, A radioactively durable melamine-styrene based polymer: highly efficient removal of Sr-90, Appl. Radiat. Isot. 149 (2019) 96-103.

[105] R. Kumar, P. Malodia, M. Kachwaha, S. Verma, Adsorptive and kinetic studies of resin for removal of $\mathrm{Cs}^{+}$and $\mathrm{Sr}^{2+}$ from aqueous solution, J. Water Chem. Technol. 41 (2019) 292-298.

[106] M. Xing, S.T. Zhuang, J.L. Wang, Adsorptive removal of strontium ions from aqueous solution by graphene oxide, Environ. Sci. Pollut. Res. 26 (2019) 29669-29678.

[107] Y. Wei, K.A.M. Salih, S. Lu, M.F. Hamza, T. Fujita, T. Vincent, E. Guibal, Amidoxime functionalization of algal/polyethyleneimine beads for the sorption of Sr(II) from aqueous solutions, Molecules 24 (2019) 3893.

[108] T. Abdollahi, J. Towfighi, H. Rezaei-Vahidian, Sorption of cesium and strontium ions by natural zeolite and management of produced secondary waste, Environ. Technol. Innovation 17 (2020) 100592.

[109] J. Liang, J. Li, X. Li, K. Liu, L. Wu, G. Shan, The sorption behavior of CHA-type zeolite for removing radioactive strontium from aqueous solutions, Sep. Purif. Technol. 230 (2020) 115874 